\title{
O Programa de Cidades Históricas': por uma política integrada de preservação do patrimônio cultural urbano
}

\section{Sandra Magalhães Correa ${ }^{2}$}

RESUMO: O Programa de Cidades Históricas (PCH), implementado a partir de 1973, foi o primeiro programa federal que investiu recursos para a recuperação do patrimônio cultural urbano. Implementado pelo Ministério do Planejamento, buscava o desenvolvimento econômico das cidades históricas e dialogava com outros assuntos em pauta naquele momento, como o desenvolvimento urbano e regional e o turismo cultural. Tinha em sua concepção uma mudança na maneira de abordar as cidades históricas: a partir do entendimento da cidade como produtora de capital, o patrimônio cultural geraria desenvolvimento econômico pelo seu consumo para a atividade turística. De 1973 a 1979, foram investidos 17,3 milhões de dólares, realizando-se 143 obras em monumentos (85\% dos investimentos); 8 cursos de qualificação de mão de obra nos três níveis (superior, intermediário e operário); 7 planos urbanísticos; 6 obras em espaços públicos (urbanos); e 10 ações de tipos diversos. Nossa análise busca entender essa política a partir do seu processo de formulação e implementação, no período de 1972 a 1979. Pretende, nesse sentido: a) avaliar as relações de poder em jogo durante a construção e a implementação do programa; b) compreender o grau de sucesso que o programa obteve na construção de um Sistema Nacional de Patrimônio Cultural, analisando sua articulação junto aos estados e outros órgãos federais; e c) avaliar o papel do programa enquanto indutor de novas práticas institucionais no campo da preservação do patrimônio cultural, especialmente com relação ao Iphan e aos estados federativos brasileiros.

PALAVRAS-CHAVE: Programa de Cidades Históricas. Descentralização. Políticas de preservação. Patrimônio cultural. Políticas de turismo.

ABSTRACT: The Historic Cities Program (PCH: 1973-1979) was the first federal program that has invested resources to the recovery of the urban cultural heritage. Implemented by the Ministry of Planning, sought economic development of historic towns and dialogued with other items on the agenda at the time, such as urban and regional development and cultural tourism. I † brought a change in the way of approach the historic towns: from the understanding of the city as a producer of capital, heritage would generate economic development through its consume
1. "Programa de Cidades Históricas" é nome pelo qual é mais conhecido o "Programa Integrado de Reconstrução das Cidades Históricas do Nordeste com sua Utilização para Fins Turísticos" (1973-1976); cuja nomenclatura foi posteriormente, alterada para "Programa Integrado de Reconstrução das Cidades Históricas (19761979)"; e, finalmente, tornou-se Programa de Cidades Históricas em 1979, denominação que será aqui adotada.

2. Coordenadora de Fomento no Departamento de Patrimônio Material e Fiscalização do Instituto do Patrimônio Histórico e Artístico Nacional, mestre em Arquitetura e Urbanismo pela UNB e especialista pelo CECRE/UFBA. E-mail: $<$ sandramagacorrea@gmail. com>. 
3. Para que o texto fique mais compreensível, utilizaremos a nomenclatura atual do órgão federal responsável pela preservação do patrimônio cultural: Instituto do Patrimônio Histórico e Artístico Nacional - Iphan. Entretanto, essa instituição, criada em janeiro de 1937 como Serviço do Patrimônio Histórico e Artístico Nacional, teve seu nome alterado cinco vezes: Diretoria de Patrimônio Histórico e Artístico Nacional (Dphan), em 1946; Instituto do Patrimônio Histórico e Artístico Nacional (Iphan), em 1970; Secretaria do Patrimônio Histórico e Artístico Nacional e Fundação Pró-Memória (Sphan/Pró-Memória estrutura dupla de administração direta e indireta), em 1979; Instituto Brasileiro do Patrimônio Cultural (IBPC), em 1990; e, novamente, Instituto do Patrimônio Histórico e Artístico Nacional (Iphan), em 1994, nome que se mantém até hoje. by the tourism. From 1973 to 1979 it was invested 17.3 million dollars, performing 143 works on monuments ( $85 \%$ of investments); 8 hand-to-work training courses in three levels (top, middle and working class); 7 urban plans; 6 works in public spaces (urban); and 10 shares of various types. Our analysis seeks to understand this policy from its formulation and implementation in the period from 1972 to 1979. The aim, in this sense, is: a) to assess the power relations at play during construction and implementation of the Program; b) to understand the degree of success that the program achieved in building a national system, analyzing its relationship with states and other federal agencies; and c) to evaluate the role of Program while inducing new institutional practices in the field of preservation of cultural heritage, especially with regard to Iphan.

KEYWORDS: Programa de Cidades Históricas. Descentralization. Heritage Policies. Cultural Heritage. Tourism Policies.

O Programa de Cidades Históricas (PCH: 1973-1979) foi o primeiro programa federal que investiu recursos para a recuperação do patrimônio cultural urbano. Implementado pelo Ministério do Planejamento visava o desenvolvimento econômico das cidades históricas e dialogava com outros assuntos em pauta na década de 1970, como o desenvolvimento regional e o turismo cultural.

Tinha em sua concepção, em seus critérios de análise, e nos seus métodos de mensuração de eficiência, uma mudança na maneira de abordar a degradação das cidades históricas: a cidade era compreendida enquanto produtora de capital e bem de consumo e o patrimônio como fator de desenvolvimento econômico por meio de seu aproveitamento pelo turismo, "ensejando a criação de um fluxo de recursos necessários a sua autoconservação".

A importância de conhecê-lo decorre de diversas questões, entre elas: sua formulação e coordenação pelo órgão de planejamento do governo federal e não pela instituição responsável pela política de preservação do patrimônio cultural brasileiro (o Instituto do Patrimônio Histórico e Artístico Nacional - Iphan ${ }^{3}$; a perspectiva de se efetivar como uma política integrada, ou seja, em que outros órgãos federais efetivassem ações com o mesmo foco, possibilitando maior eficiência aos investimentos públicos; a descentralização, por meio de sua execução pelos estados; o objetivo de contribuir para o desenvolvimento econômico da região Nordeste; a aplicação significativa de recursos na área de patrimônio cultural, especialmente se comparada à capacidade de investimentos do Iphan até a década de 1970. Tais temas continuam atuais e, apesar disso, o programa é, relativamente, pouco estudado, considerando sua importância para a área de preservação do patrimônio cultural.

De 1973 a 1979 foram investidos 17,3 milhões de dólares, realizandose 143 obras em monumentos (85\% dos investimentos); 8 cursos de qualificação de mão de obra nos três níveis (superior, intermediário e operário); 7 planos urbanísticos; 6 obras em espaços públicos (urbanos); e 10 ações de tipos diversos.

Este artigo, que é uma síntese da pesquisa que resultou em dissertação de mestrado apresentada ao Programa de Pós-Graduação em Arquitetura e Urbanismo da Universidade de Brasília (UnB) em 2012, busca entender o processo de formulação e implementação do PCH, no período de 1972 a 1979. 
Com base em conceitos emprestados da Ciência Políitica, consideramos - Programa de Cidades Históricas como uma política pública com características de programa, na medida em que teve definidos os objetivos e recursos a serem aplicados previamente à sua implementação ${ }^{4}$. Essa definição determinou o recorte temporal desta pesquisa: de 1972 (quando foi publicada a Exposição de Motivos 301-B, de 22 de dezembro de 1972, que instituiu um grupo de trabalho para formulação do programa) a 1979 (data de publicação da Exposição de Motivos 320, de 08 de novembro de 1979, que transferiv o PCH ao lphan). Apesar de muitos considerarem que o programa continuou após sua incorporação ao Iphan em 1979, entendemos ser esse ano seu marco de encerramento enquanto modelo proposto em 1972. Isso porque, além de haver uma mudança significativa de estrutura - ele passa a ser coordenado pelo Iphan e não mais pelo Ministério do Planejamento -, a partir de 79 não foi definido o montante de recursos que seria destinado ao programa, apenas referida a utilização do saldo existente no Fundo de Desenvolvimento de Programas Integrados (FDPI) para os compromissos já assumidos. Ademais, os objetivos do programa tornaram-se bem mais amplos, aproximando-se bastante da missão institucional do Iphan e, portanto, em nosso entendimento, passaria a incorporar a política permanente do órgão.

Contudo, na primeira parte deste texto retroagimos à década de 1960 com vistas a identificar as articulações e os discursos dos agentes na formulação do PCH, as demandas, e mesmo outras políicas que ocorriam no período imediatamente anterior a sua implementação e que se relacionam de alguma forma ao programa. Considerando os diversos enfoques que poderiam ser utilizados para esta análise, e diante de farta documentação disponível, decidimos investigá-lo a partir do aparelho de Estado, cujos principais representantes institucionais foram o Ministério do Planejamento e o Iphan. A partir dessas instituições, identificaram-se outros agentes, como o Ministério da Fazenda, a Unesco, a Embratur, os estados brasileiros e, mais tardiamente, a Comissão Nacional de Regiões Metropolitanas e Política Urbana (CNPU). Entretanto, esses foram tratados de maneira secundária, como geradores de inputs aos dois primeiros. Dos agentes institucionais, foram identificados os burocratas que tiveram papel chave na formulação da política e mais atenção dispensada com relação à documentação consultada.

As fontes foram a bibliografia existente e fontes primárias sobre o planejamento estatal nas décadas de 1960 e 1970, a cooperação do Iphan com a Unesco na década de 1960 e as diretrizes desse organismo internacional à época; sobre os Encontros de Governadores e a constituição do Conselho Federal de Cultura; e sobre as políticas de preservação do patrimônio cultural, nos âmbitos nacional e internacional, das décadas de 1960 e 1970. Teve relevante importância, a pesquisa documental referente à burocracia administrativa do Programa de Cidades Históricas, ou seja, normas de funcionamento, correspondências, relatórios de atividades, relatórios de avaliação etc., localizados no Arquivo Central do Iphan em Brasília e no Arquivo da Superintendência do Iphan em Pernambuco, bem como entrevistas realizadas com o ex-coordenador do Programa de Cidades Históricas, Henrique Oswaldo de Andrade.
4. Ver Maria das Graças Rua (2009) e Celina Souza (2006). 
5. Ver Benicio Viero Schmidt, (1983, p. 107).

6. Cf. Brasil (1967)

7. Cf. José Camilo Santos Filho (1992, p. 220)
Descentralização, urbanização do território brasileiro e desenvolvimento do turismo: o contexto de criação do Programa de Cidades Históricas

Pouco antes da formulação do PCH, no fim da década de 1960, destacam-se duas medidas gerais que colocaram as estruturas administrativa e política municipais em articulação com o governo federal: a criação do Fundo de Participação dos Municípios (FPM) em 1967, e a implementação dos Planos para o Desenvolvimento Local Integrado (PDLI), no âmbito do Plano de Ação Concentrada (PAC). Essas ações, segundo Schmidt ${ }^{5}$, fortaleceram a estrutura de tomada de decisão ao nível do governo municipal.

Plano de Ação Concentrada (PAC), elaborado no Governo Costa e Silva e implementado em 1969, era parte de um programa maior, o Plano Estratégico de Desenvolvimento (PED - 1968/1970). Sua função central estava orientada no sentido da coordenação das instâncias federadas da nação brasileira em suas ações para o desenvolvimento, sobretudo no contexto de (possíveis e efetivas) retomadas dos investimentos públicos para recuperação do crescimento econômico do país.

Nesse sentido, percebe-se que o governo brasileiro delineava um discurso de descentralização de suas políticas, especialmente em programas e ações que buscassem o desenvolvimento regional. $\bigcirc$ Decreto-Lei 200, de 1967, que dispõe sobre a organização da Administração Federal, explicita isso ao estabelecer a descentralização como um dos seus princípios, em especial em seu artigo 10:

Art. 10. A execução das atividades da Administração Federal deverá ser amplamente descentralizada.

$\S 1^{\circ} \mathrm{A}$ descentralização será posta em prática em três planos principais: (...)

b) da Administração Federal para a das unidades federadas, quando estejam devidamente aparelhadas e mediante convênio; (...)

$\S 4^{\circ}$ Compete à estrutura central de direção o estabelecimento das normas, critérios, programas e princípios, que os serviços responsáveis pela execução são obrigados a respeitar na solução dos casos individuais e no desempenho de suas atribuições.

$\S 5^{\circ}$ Ressalvados os casos de manifesta impraticabilidade ou inconveniência, a execução de programas federais de caráter nitidamente local deverá ser delegada, no todo ou em parte, mediante convênio, aos órgãos estaduais ou municipais incumbidos de serviços correspondentes. $(\ldots)^{6}$.

Observe-se que o decreto propõe a descentralização para a execução das políticas, mantendo o poder de decisão no governo federal, estabelecendo uma posição hierárquica entre União e outros entes federados:

Dentro do espírito das forças que tomaram o poder central, essa descentralização [estabelecida pelo Decreto-Lei 200] assumiu um caráter autoritário e tecnocrático, onde o que podia ou devia ser descentralizado foi decidido na cúpula, cabendo aos órgãos descentralizados apenas o poder de execução das instâncias superiores ${ }^{7}$. 
É possível que a descentralização fosse vista como um risco à estabilidade do governo, na medida em que empoderaria a unidade municipal (muito mais próxima da população e portanto mais suscetível às pressões), em um momento de crescimento da reação da sociedade civil à repressão. Entretanto, tecnicamente, era uma opção para enfrentar o desafio de coordenar um país constituído por um grande território e cingido pela desigualdade regional. Nesse sentido, a União seria o ente federativo responsável por concatenar os interesses locais em prol de um (suposto) interesse nacional. Esse conflito talvez explique porque apenas alguns setores do governo fizeram essa opção: ao mesmo tempo em que foram estabelecidas políticas fiscais altamente centralizadoras, foram também efetivados programas por diversos ministérios lespecialmente do Planejamento e do Interior) em que o modelo operacional era de descentralização das ações

Ao mesmo tempo, as mudanças nos planos econômicos - internacional e brasileiro - no período após a Segunda Guerra Mundial, devido à transformação e à explosão populacional de cidades, forçaram uma transformação nas políticas urbanas e de preservação do patrimônio cultural. $\bigcirc$ governo central brasileiro vê-se obrigado a posicionar-se sobre a situação das cidades, reforçando, pela necessidade de componentes locais, a descentralização para execução de suas políticas.

Em 1960, a população urbana brasileira representava 45,88\% da população total, um acréscimo de $70 \%$ em relação a $1950^{\circ}$. Segundo Francisco de Oliveira ${ }^{9}$, a mudança do fenômeno urbano brasileiro nesse período está relacionada à passagem do capitalismo concorrencial então vigente no Brasil para a etapa monopolista. Esse processo inicia-se na década de 1950, tendo como principal motivação o fato de o Estado brasileiro ter sido forçado a financiar o desenvolvimento da indústria pelas restrições impostas pelos países centrais. $\bigcirc$ modelo de desenvolvimento perseguido era o de base urbanoindustrial, em que a cidade passa de bem de consumo para bem de produção ${ }^{10}$, ou seja, passa a produzir capital. Assim, o uso do solo vira um instrumento de valorização financeira, e a estagnação do patrimônio construído passa a significar dinheiro perdido, ou seja, as cidades antigas seriam entraves para as atividades inerentes ao processo de concentração, centralização e reprodução do capital. Nesse processo, as cidades e centros históricos sofriam com o crescimento acelerado e a pressão demográfica, metropolização de algumas regiões, implantação de indústrias em seus arredores e abertura de estradas, afluxo turístico desordenado, ou, do outro lado da moeda, com a estagnação econômica ou o esvaziamento populacional. Responsável pela preservação do patrimônio cultural brasileiro, o lphan deparava-se com pressões das próprias prefeituras para destruição de seus centros históricos ou a falta de recursos em âmbito local para sustentação mínima das atividades municipais. A especulação imobiliária passou a ser um atributo importante do processo de urbanização brasileira, tendo o Estado como propulsor:
8. Ver Álvaro Pessoa (1981, p. XVI).

9. Ver Francisco de Oliveira (1982).

10. Ver Flávio Villaça (1999, p. 200). 
11. Cf. Vera Milet (1988, p. 161-164).

12. Ibid. (p. 112-113).
A ação modernizadora estatal (...) mantém laços orgânicos com a iniciativa de cidadãos privados, bem como com a nova forma de capital, o imobiliário, cuja razão histórica se consubstancia, justamente, na apropriação do solo e produção do espaço urbano e na substituição de edificações antigas por construções modernas de novos conteúdos funcionais. Por outro lado, o crescimento industrial e seus correlatos (...) possibilitaram a integração de núcleos antigos (...) ao processo de urbanização e de especulação imobiliária ${ }^{11}$.

A pressão da especulação imobiliária sobre os centros históricos não foi exclusiva do Brasil. Por motivos diferentes, outros países também tentavam encaixar - patrimônio na nova cidade capitalista. Em encontro organizado pelo Departamento de Assuntos Culturais da Organização dos Estados Americanos (OEA), essa contradição foi explicitada, e a solução foi articular os interesses econômicos à preservação do patrimônio cultural. Haveria, portanto, uma saída: na cidade que deve reproduzir o capital, o patrimônio deve ser objeto de consumo, sendo parte dos recursos econômicos nacionais. As Normas de Quito, de 1968, resultantes desse encontro, assumirão essa perspectiva econométrica:

(...) as medidas preservacionistas encontram-se diretamente associadas aos planos, projetos e equipamentos de interesse turístico que viabilizem o retorno econômico do investimento feito no monumento, ficando, inclusive, formalmente expressas as vinculações entre os interesses protecionistas e os interesses do capital internacional' ${ }^{12}$.

A oportunidade vislumbrada a partir do turismo, extremamente relacionada a esse contexto, começa a ser objeto de proposição da Unesco a partir de 1965, quando a organização inicia um programa de desenvolvimento do turismo relacionado aos patrimônios cultural e natural. $\bigcirc$ Iphan pleiteia, e consegue, o apoio técnico do organismo internacional. Estabelece-se estreita e profícua relação, a fim de receber especialistas para elaboração de estudos e planos voltados ao patrimônio cultural brasileiro - com foco nas cidades e visando à inserção desses locais em um plano nacional de turismo cultural.

A documentação consultada no Arquivo Central do Iphan, no Rio de Janeiro, apresenta uma intensa correspondência entre o Iphan e o Ministério das Relações Exteriores (MRE), em especial com o embaixador Carlos Chagas Filho, pelo menos a partir de 1964. Pela documentação percebe-se que Renato Soeiro e Rodrigo M. F. de Andrade participavam das conferências da Unesco, conheciam de maneira profunda as discussões e os documentos resultantes e estavam bastante afinados com os movimentos no âmbito internacional. Dessa forma, nos parece que ambos identificavam uma oportunidade nos programas de assistência técnica oferecidos pela Unesco, possibilitando o alargamento da ação do Iphan frente às restrições de sua estrutura administrativa.

Em junho de 1966, em carta a Rodrigo M. F. de Andrade, Renato Soeiro comenta sobre projeto do Iphan que visa a solicitar recursos da Unesco no âmbito dos programas de Incremento ao Turismo e de Recuperação de Recursos Naturais. Após negociações mediadas pelo embaixador Carlos Chagas Filho para pleitear apoio da Unesco, o Brasil recebe visita de representantes da organização 
visando analisar a situação brasileira. Em outubro de 1966, Rodrigo M. F. de Andrade envia carta ao Ministro da Educação e Cultura, Raymundo Augusto de Castro Moniz de Aragão, na qual pede que a delegação brasileira apoie o

Plano do Incentivo ao chamado Turismo Cultural, importando em concurso financeiro de estabelecimentos de crédito internacional, sob responsabilidade da UNESCO, para conservação e recuperação de monumentos e proteção da natureza nos territórios dos Estados membros. (...). Pleiteamos a aplicação dele ao Brasil. Se a Conferência Geral tiver de incluir no orçamento recursos destinados a favorecê-lo, há grande conveniência de que a Delegação brasileira, sob sua presidência, apoie a medida ${ }^{13}$.

Em dezembro do mesmo ano, a revista El Correo, periódico da Unesco, é dedicada ao turismo, após o estabelecimento, pela Assembleia Geral das Nações Unidas, do ano de 1967 como "Ano Internacional do Turismo".

No texto, que toma praticamente todo o periódico, lembra-se que em 1963 foi realizada Conferência das Nações Unidas sobre Turismo e Viagens Internacionais. A partir daí, são citadas diversas estatísticas realizadas - em países desenvolvidos ou não - sobre o turismo e sua rentabilidade. A matéria é extremamente otimista, vislumbrando no turismo a solução para inserir o patrimônio cultural como elemento fundamental para o desenvolvimento econômico dos países: "fenómeno económico y social" 14.

Afirma-se que, desde 1964, a Unesco visa ao ajuste de um programa que pretende integrar a conservação e a restauração de monumentos e lugares históricos com um plano de desenvolvimento de turismo, com base na rentabilidade dos investimentos turísticos, ou seja, o periódico oficial do organismo internacional representa o discurso, em 1966, de que o turismo era o grande negócio para o patrimônio cultural.

El concepto es nuevo; en muchos paises solo podrá lograrse la conservación del património monumental, y servir con ello fines educativos y culturales cuando monumentos y sítios históricos se hayan hecho económicamente rentables gracias al turismo, fenómeno moderno por excelencia ${ }^{15}$.

No ano seguinte, era concluída a missão do consultor da Unesco no Brasil, Michel Parent, que teria por objetivo "dar parecer sobre o auxílio pleiteado para a execução de um plano de serviços desta repartição, cuja inclusão é pretendida no programa das Nações Unidas de Incentivo ao Turismo Cultural"16.

$\bigcirc$ francês fez duas visitas ao Brasil ${ }^{17}$, percorrendo diversas cidades, de norte a sul do país $^{18}$. Em seu relatório ${ }^{19}$, Parent enfatiza o contato estreito que teve com os funcionários do então Iphan, especialmente Renato Soeiro e Rodrigo Melo Franco de Andrade, citando também autoridades ligadas à recém-criada Empresa Brasileira de Turismo (Embratur) ${ }^{20}$. Ressalta que

Qualquer "planejamento global para a conservação dos bens artísticos e de determinados patrimônios naturais" desejado pelo governo e levado em consideração pela Unesco deve, como enfatiza o embaixador Chagas, ser realizado "por meio de sua integração nos projetos de desenvolvimento do país"21.
13. Cf. Rodrigo Mello Franco de Andrade (1966, p. 1).

14. Ver Unesco (1966a, p. 5).

15. Ibid. p. 10 .

16. Cf. Renato Soeiro (1967).

17. De $24 / 11 / 1966$ a 08/01/1967 e de $19 / 04 / 1967$ a $01 / 06 / 1967$.

18. Parati, Cabo Frio, lagoa de Araruama e Rio de Janeiro, no RJ; São Paulo e arredores, em SP; Anchieta e Serra, no ES; Salvador, Cachoeira e Belém de Cachoeira, na BA; Olinda, Igarassu, Paulista, Recife e arredores, em PE; São Luís e Alcântara, no MA; Belém, no PA; Brasília, no DF; Goiás, em GO; Ouro Preto, Sabará, Mariana, Congonhas do Campo, São João Del Rei, Tiradentes, Diamantina e Belo Horizonte, em MG; Paranaguá, os sambaquis do litoral, Vila Velha e Foz do Iguaçu, no PR; São Miguel e as reduções indígenas, no RS.

19. Publicado pela Unesco em 1968, em francês, e pelo Iphan em 2008, traduzido em português e reproduzido o original.

20. A Embratur foi criada em 1966.

21. Cf. Michel Parent apud Claudia Feierabend Baeta Leal (2008, p. 42). 
22. Ver Cláudia Baeta Leal (2008, p. 27).

23. Cf. Michel Parent (1968, p. 13).

Michel Parent afirma também que a preservação só poderá ser alcançada mediante sua inclusão no planejamento urbano do município, bem como por seu aproveitamento turístico. Em vários trechos, ressalta a necessidade de integração aos planos de desenvolvimento globais, enfatizando a necessidade de a política de preservação do patrimônio cultural ser articulada a outras políticas federais, especialmente de turismo, habitação e planejamento, bem como ser compartilhada pelos demais entes federativos, estados e municípios. Recomenda, claramente, que - Iphan se torne um órgão coordenador da políitca de preservação do patrimônio cultural, pois só assim será possível enfrentar os amplos desafios existentes. Para isso, seria necessária uma completa reestruturação do órgão. Segundo Cláudia Baeta Leal22, o relatório de Parent tinha duas perspectivas: chamar a atenção do governo brasileiro para as potencialidades turísticas de seu patrimônio cultural e revelar aos organismos internacionais a excepcionalidade desse patrimônio, que mereceria, portanto, apoio técnico internacional para a sua preservação.

Apesar de ser um consultor da Unesco, é importante diferenciar a "fala" de Parent do discurso constante no artigo sobre turismo na revista El Correo. Parent é bem mais prudente com relação aos milagres que podem ser alcançados pelo turismo, aproximando-se de outra corrente em voga naquele momento: a do planejamento urbano e regional.

El plan de desarrollo cultural debe ser global y estar integrado al plan de desarrollo general (...) El primer problema por resolver en este caso es la descentralización de la actividad y la diseminación de las empresas, medidas a las que deverá seguir una renovación agrária. El desarrollo del turismo está condicionado por estas reformas de estructura, pero a su vez, al aportar su contribución al desarrollo econômico y al mejoramiento de las condiciones de vida de la población, el turismo puede dar nuevo vuelo a muchas de desarrollo. La creación de los nudos principales de una red turística deberá tener muy en cuenta esta circunstancia ${ }^{23}$.

Parent chama a atenção para os conjuntos arquitetônicos abandonados pela elite e tomados pela população pobre, que os habitava em condições insalubres, já que os edifícios se encontravam em más condições de conservação e superlotados, tais como os de Salvador e São Luís. Ressalta, no entanto, que a expulsão dessa população faria com que o patrimônio perdesse boa parte de seu significado e que seria no mínimo injusto, e mesmo intolerável, que essas comunidades fossem alijadas pelo pretexto de que o mundo, finalmente, teria reconhecido o valor desses bens culturais.

Parent ainda menciona a qualidade técnica do quadro de pessoal do Serviço do Patrimônio Histórico e Artístico Nacional, mas ressalta a necessidade de se integrar suas ações às áreas de planejamento do país. Por isso, acredita que todas as ações propostas em seu relatório devem ser coordenadas em nível federal, à semelhança do que já fazia o Iphan. Por fim, Parent elabora seu relatório totalmente favorável ao apoio da Unesco ao Brasil para aproveitamento de seu patrimônio para fins turísticos, indicando a necessidade de elaboração de planos específicos para algumas cidades históricas. 
Em 1968, o Iphan pleiteia a extensão do apoio técnico da Unesco até 1972, e a elaboração de planos para cidades históricas brasileiras é iniciada por consultores da organização internacional. Nas correspondências sobre o apoio internacional, é mencionada a importância do

equacionamento, pela primeira vez, de um plano de turismo de âmbito nacional e da iniciativa do Conselho Nacional de Turismo [que] reforça a necessidade da organização de projetos como os estabelecidos para Salvador, Ouro Preto e Parati24.

Em Parati, o plano de desenvolvimento urbano é elaborado pelo consultor Frédéric de Limburg Stirum, que baseou seus estudos "na preservação das características naturais e culturais do Município e no incremento do turismo, da construção civil, da agricultura, da pesca e da exploração regulamentada de madeiras nativas"25. Já o plano do Pelourinho (do escritório inglês Shankland \& Cox) buscava a renovação da área central de Salvador, com elevação do padrão habitacional, bloqueada pela Fundação do Patrimônio Artístico e Cultural da Bahia, que pretendia manter a população residente na área. Em Ouro Preto, o português Viana de Lima delineou um plano diretor, constando de plano viário, de zoneamento e de diretrizes para intervenções na parte histórica ${ }^{26}$.

A intensa e longa comunicação entre técnicos e direção do Iphan e os especialistas, documentos (resoluções e publicações) e eventos da Unesco levamnos a concluir que o órgão nacional, para além de consciente, articulava-se política e tecnicamente para utilizar os instrumentos considerados à época, internacionalmente, como adequados para a preservação do patrimônio cultural. Por outro lado, não se pode afirmar que o Iphan encontrava-se preparado para enfrentar os problemas que as cidades históricas apresentavam, até porque o governo federal como um todo também se debatia para formular uma primeira política urbana nacional (entendendo-se que a questão das cidades históricas era parte da problemática urbana e regional).

Se essa contínua cooperação/alinhamento com a Unesco já coloca em questão o suposto isolamento do Iphan na década de 1960, apontado por alguns autores $^{27}$, a busca do órgão federal pela aproximação dos demais entes federativos (estados e municípios), bem como com as universidades e a sociedade civil, com vistas a ampliar os agentes da política de preservação do patrimônio cultural, nos parece dar certeza do equívoco desse entendimento.

Os Encontros de Governadores para Preservação do Patrimônio Cultural, organizados pelo MEC, são a ação mais visível desse movimento. Relacionam-se, fundamentalmente, à criação do Conselho Federal de Cultura (CFC), em 1966, que tinha como um de seus principais objetivos a descentralização por meio de conselhos e órgãos específicos de cultura nos estados e municípios - um "Sistema Nacional de Cultura", no qual o patrimônio cultural teria papel importante.

$\bigcirc$ projeto do conselho surge em 1965, a partir de uma comissão presidida por Josué Montello e formada por Adonias Filho, Augusto Meyer, Rodrigo Melo Franco de Andrade e Américo Jacobina Lacombe. Ao conselho cabia,
24. Cf. Renato Soeiro (1968, p. 1).

25. Cf. Márcia Sant'Anna (1995, p. 155).

26. Não nos aprofundaremos no conteúdo desses planos. Márcia Sant'Anna abordou de forma mais detalhada tantos os planos realizados sob cooperação com a Unesco como os financiados pelo Programa de Cidades Históricas. Ver Márcia Sant'Anna (1995).

27. Em especial, ver José Reginaldo Santos Gonçalves (1996) e Maria Cecília Londres Fonseca (2005). 
28. Desde que reconhecidos pelo conselho.

29. Ver Lia Calabre (s/d, p. 6).

30. Cf. Tatyana de Amaral Maia (2010, p. 5).

31. Cf. Tatyana de Amaral Maia (2011, p. 72).

32. Ver Tatyana de Amaral Maia (2011, p. 75-76). inicialmente, assessorar o Ministro da Educação e Cultura na normatização, na fiscalização e na distribuição de recursos às instituições culturais ligadas ao MEC. Sua atuação abrangia as instituições nacionais e estaduais de cultura, as universidades federais e os institutos particulares ${ }^{28}$. Desde sua criação, quando apenas dois estados possuíam conselhos estaduais de cultura, até setembro de 1971, foram criados e colocados em funcionamento conselhos em outros 20 estados brasileiros ${ }^{29}$. Os intelectuais ligados à criação do Iphan foram fundamentais na criação e na atividade do Conselho Federal de Cultura. Segundo Maia:

\begin{abstract}
A presença maciça de representantes da Câmara de Patrimônio na constituição da Comissão [de Legislação e Normas] pode ser analisada a partir de duas sentenças: primeiro, a importância da área do patrimônio para o Conselho; segundo, a experiência bem sucedida das políticas de preservação do patrimônio instituídas pelo Estado desde a década de $1930^{30}$.
\end{abstract}

Esse protagonismo parece ter feito com que o conselho incorporasse o discurso da ameaça constante ao patrimônio cultural brasileiro pela falta de infraestrutura e investimentos, relatada nos encontros realizados pelo CFC com autoridades dos governos federal, em 1968, "para articularem seus esforços ao da União em defesa do ameaçado patrimônio cultural através da constituição de um sistema nacional de cultura" ${ }^{\prime \prime}$.

Rodrigo M. F. de Andrade foi conselheiro até 1969, quando Renato Soeiro substituiu-o. Em julho de 1970, é criado o Departamento de Assuntos Culturais (DAC), para cumprir as funções executivas que vinham sendo realizadas pelo conselho. Soeiro é nomeado diretor do DAC, ao mesmo tempo em que era a autoridade máxima do Iphan, consolidando, nesse sentido, a importância política do patrimônio na área de cultura do governo federal.

Em abril de 1970, o conselho organizou, em Brasília, o Encontro dos Governadores sobre a Defesa do Patrimônio Histórico e Artístico do Brasil. Segundo Maia, o próprio ministro da Educação, Jarbas Passarinho, empenhou-se na realização do encontro, esperando que a reunião acalmasse os ataques da imprensa sobre a situação de degradação em que se encontrava o patrimônio cultural brasileiro ${ }^{32}$.

A Renato Soeiro foi atribuída a responsabilidade de apresentar aos participantes a pauta do encontro, destacando a importância dos estados e municípios para a preservação do patrimônio. Podemos considerar que esse encontro representou o passo inicial para a uma desejada articulação entre as esferas dos poderes executivos dos governos federal e estaduais, e também com as universidades, os arquivos e a sociedade civil (representada pelos conselhos estaduais e municipais). Essa articulação teria como "cabeça" o Iphan, representando a União, que buscava uma estrutura simétrica nos estados e municípios, com ação supletiva nos diferentes níveis de governo, replicando o que tinha sido empreendido no âmbito do CFC.

Parece-nos que o principal resultado do encontro foi incluir na agenda política das esferas estaduais a preservação do patrimônio histórico e artístico 
brasileiro. Assim, ele teria funcionado como uma preparação para o segundo encontro, que se aprofundaria na temática e contaria com discussões trazidas pelos próprios estados.

A primeira sessão do II Encontro de Governadores, realizado em Salvador no ano de 1971, teve como um dos temas os resultados do Encontro de Brasília, a partir dos relatos dos estados sobre as providências tomadas para o cumprimento do compromisso anteriormente firmado. Renato Soeiro apresentou aos participantes os desafios do Iphan, e sua relação com o Compromisso de Brasília ${ }^{33}$, ressaltando que o instituto vinha exorbitando suas funções devido a não responsabilização dos estados e municípios na missão de preservar o patrimônio histórico e artístico regionais. Destaca a criação do Departamento de Assuntos Culturais, em julho de 1970 - "três meses depois do I Encontro de Brasília e simultaneamente, a nova condição do Patrimônio, que passou desde então a ser um órgão autônomo - o Iphan -, com maior flexibilidade administrativa e financeira"34. Também defende que se considere como resultado daquele evento a Resolução 94/1970, do Tribunal de Contas da União, que permitiu a utilização de 5\% do Fundo de Participação dos Estados e Municípios para a preservação do patrimônio histórico e artístico. Relaciona ao Encontro de Brasília a criação de órgão específico para a proteção do patrimônio histórico e artístico estadual em cinco estados, e órgãos ou Conselhos de Cultura em três. Assim, percebemos que houve uma preocupação em demonstrar o comprometimento político, observandose o expressivo número de instâncias criadas em, relativamente, pouco tempo: 8 novas estruturas em cerca de um ano.

No Compromisso de Salvador, que consolidou os debates do II Encontro, ficou definida uma série de recomendações, das quais destacamos: 1) que fossem considerados prioritários, para obtenção de financiamento, os planos urbanos e regionais que envolvessem áreas com bens culturais e naturais protegidos por lei; 2) a convocação do Banco Nacional de Habitação e dos demais órgãos financiadores de habitação para colaborarem no custeio das obras em edifícios tombados; 3) que o Iphan fosse contemplado com adequados recursos humanos e financeiros; 4) a convocação dos órgãos responsáveis pelo planejamento do turismo para sensibilização sobre os problemas de valorização, utilização e divulgação dos bens culturais e naturais; 5) que os órgãos de turismo estudassem medidas para a implantação preferencial de pousadas em bens tombados.

Com isso pretendemos demonstrar que, apesar da constituição de um "sistema" ser uma discussão iniciada a partir do Conselho Federal de Cultura, os diretores do Iphan, paralelamente, contribuíram para a definição desse objetivo no CFC; e os Encontros dos Governadores trouxeram essa pauta, especificamente, para o patrimônio cultural. Esse será um elemento importante na elaboração do Programa de Cidades Históricas.

Ainda devemos lembrar que é também na década de 1960 que ocorre a institucionalização da atividade turística no Brasil, seguindo uma tendência mundial. Sendo o patrimônio cultural considerado um de seus principais atrativos,
33. Ver Compromisso de Brasília. Disponível em $<$ http://portal.iphan.gov. br>. Acesso em 05 mai.2012.

34. Cf. Ministério da Educação e Cultura (1973, p. 51). 
35. Representantes: Ministério da Educação e Cultura - Renato Soeiro (diretor do Departamento de Assuntos Culturais e do Iphan), Indústria e Comércio - Ney Tinoco (diretor da Embratur), e do Interior Edileusa Rocha (da Sudene). Representaram o Miniplan: Affonso de Lima Vitule (secretário geral adjunto), Fernando Quintela (coordenador do GT) e Luiz Siqueira (assessor - secretário executivo do GT). a vinculação, por parte do próprio Iphan, dessas duas atividades nos pareceu uma aguda percepção das motivações que interessariam aos governos estaduais, que viram na proposta a possibilidade de gerar riquezas em suas regiões.

Com a apresentação bastante sucinta desse contexto imediatamente anterior à criação do Programa de Cidades Históricas, buscamos argumentar acerca dos discursos e debates, a partir de diversos agentes, relacionados ao patrimônio cultural - especialmente, o edificado urbano - que desde o início da década de 1960 parecem convergir para o que viria a ser o PCH. Apesar de não ter sido encontrada documentação que explicite vinculação direta entre as ações empreendidas pelo Iphan e a criação do PCH, nossa investigação parece apontar, considerando a coerência entre os conceitos presentes no programa e os debates ocorridos no período imediatamente anterior a sua criação, uma continuidade da política que vinha sendo formulada/implementada pelo Iphan.

Formulação e implementação do Programa Integrado de Reconstrução das Cidades Históricas (PCH) - 1972-1979

Não se sabe exatamente como se deu a motivação original para a criação do Programa Integrado de Reconstrução das Cidades Históricas do Nordeste. Segundo Henrique Oswaldo de Andrade, coordenador do programa de 1975 até seu encerramento, o PCH teria surgido a partir de uma visita de João Paulo dos Reis Velloso, Ministro do Planejamento e Coordenação Geral (Miniplan), a Olinda em fins de 1972 ou início de 1973. Velloso teria se sensibilizado com a situação da cidade, apresentada por Ayrton Carvalho, diretor do $1^{\circ}$ Distrito Regional do Iphan (Pernambuco), que também teria relatado a situação do órgão, com recursos humanos e materiais insuficientes para enfrentar a degradação dos centros históricos brasileiros. Ademais, também são indicados por alguns autores que as notícias veiculadas na imprensa sobre a destruição de várias cidades históricas, e que pressionaram o MEC a realizar os Encontros de Governadores, teriam gerado o fato políico para a criação do programa.

Entretanto, o documento mais antigo encontrado no Arquivo Central do Iphan sobre o "Programa Integrado de Reconstrução das Cidades Históricas do Nordeste, com sua Utilização para Fins Turísticos" é a Exposição de Motivos 301-B, de 22 de dezembro de 1972 (EM 30 1-B/72), que não cita nenhum dos fatos acima. Elaborada conjuntamente pelos Ministérios do Planejamento e Coordenação Geral e de Educação e Cultura, determinava a constituição de Grupo de Trabalho Interministeria| ${ }^{35}$ para formular, em versão preliminar, o Programa de Reconstrução das Cidades Barrocas do Nordeste. Esse documento justifica a criação do programa por dois motivos principais: a necessidade de recuperar cidades coloniais de relevante interesse histórico e artístico, e a possibilidade dessas cidades, integradas em roteiros turísticos, atraírem investimentos à Região Nordeste. 
resultado dos trabalhos do GT foi entregue em maio de 1973, agregando as localidades a serem atendidas em três grupos prioritários: 1) dotadas de infraestrutura adequada ao turismo; 2) "em vias de desaparecimento pela destruição"; e 3) sem infraestrutura adequada, mas em condições não tão precárias quanto às localidades do segundo grupo ${ }^{36}$. Apesar de a listagem de cidades não ter constituído uma regra rígida ${ }^{37}$, os projetos apresentados pelos estados até agosto de 1974 estavam, em sua maioria, contemplados na Exposição de Motivos e seus anexos, não sendo, portanto, a prática completamente dissonante do estabelecido na norma.

$\bigcirc$ principal objetivo do programa, constante na referida Exposição de Motivos, era a preservação dos monumentos tombados, tornando-os economicamente viáveis por meio de seu uso para a atividade turística. Buscava-se criar um círculo virtuoso de sustentação econômica, ou seja, após os investimentos iniciais do programa, a economia do turismo local financiaria a conservação dos monumentos.

A participação efetiva dos municípios e dos estados dava-se por meio de uma contrapartida financeira mínima de $20 \%$ para execução de obras para implantação de estradas, energia e saneamento básico, bem como para estudos e planos de desenvolvimento local; os $80 \%$ restantes viriam do Fundo (federal) de Desenvolvimento de Programas Integrados (FDPI) para financiar projetos que se enquadrassem nas regras do programa. Assim, os estados deveriam apresentar os monumentos a serem recuperados, com respectivas propostas de uso, e as obras de contrapartida que seriam realizadas, para avaliação pela Seplan sobre sua viabilidade econômica. Apesar de envolvido desde os primeiros momentos da estruturação do PCH, ao Iphan coube, nessa primeira etapa, apenas analisar as intervenções arquitetônicas dos monumentos. Se por um lado isso garantiu legitimidade exclusiva para análise dos aspectos relacionados à restauração dos monumentos, por outro excluiu a possibilidade da instituição opinar sobre a conveniência da intervenção proposta - seja no que se refere à relevância do monumento e o uso indicado, seja com relação ao efeito que essas intervenções poderiam causar para a preservação do conjunto. Entretanto, foi estabelecido que - Iphan receberia recursos para atender às cidades classificadas como terceira prioridade, cuja aplicação era de sua exclusiva responsabilidade, não necessitando de aprovação do Ministério do Planejamento.

Em 31 de maio de 1973, João Paulo dos Reis Velloso e Jarbas Passarinho ${ }^{38}$ emitiram a Exposição de Motivos 076-B (EM 076-B/73) $)^{39}$, que criou, efetivamente, o "Programa Integrado de Reconstrução das Cidades Históricas do Nordeste, com sua Utilização para Fins Turísticos". Seu conteúdo reproduz o relatório apresentado pelo grupo de trabalho.

As críticas ao programa já se iniciaram no ano seguinte de sua criação: em novembro de 1974, Augusto da Silva Telles, assessor do Iphan, apresentou a palestra Planos Regionais e definição de prioridades para o Programa Integrado de Reconstrução das Cidades Históricas ${ }^{40}$, na qual criticou a escolha dos usos
36. Ver Grupo de Trabalho Interministerial, 1973. No documento, constam como prioridade 1 as cidades de Porto Seguro, Salvador e Cachoeira, na Bahia; São Cristóvão, em Sergipe; Olinda, Igarassu, Itamaracá (Forte Orange), Guararapes e Cabo Santo Agostinho, em Pernambuco; como prioridade 2 são indicadas as cidades de Laranjeiras, em Sergipe; Marechal Deodoro, em Alagoas; e Alcântara, no Maranhão. A prioridade 3 tinha como cidades indicadas: Penedo, em Alagoas; Aracati, Sobral e Aquiraz, no Ceará; Oeiras e Piracuruca (Sete Cidades) no Piauí; e São Luís, no Maranhão. Nos anexos da Exposição de Motivos, ainda constam as cidades de Santo Amaro, Jaguaribe, Ilha de Itaparica e Lençóis (BA); Tomar de Geru (SE); Porto Calvo (AL); Goiana, Paulista e Vicência (PE); Cabedelo (PB); Natal (RN); e Fortaleza (CE).

37. Segundo relatório da Delegacia Regional da Seplan/PR, de 1976, a relação de cidades constante no anexo I da EM 076-B/73 teria servido, principalmente, "como determinante inicial da grandeza dos recursos necessários aos trabalhos de recuperação e aproveitamento turístico". Cf. Ministério do Planejamento e Coordenação Geral (1973, p. 7).

38. Ministro do Planejamento e Coordenação Geral e Ministro da Educação e Cultura, respectivamente.

39. Cf. Ministério do Planejamento e Coordenação Geral (1973). Arquivo Central do Iphan em Brasília: Programa de Cidades Históricas: Caixa 89 , camisa $76 \mathrm{G}$.

40. I Seminário de Estudos sobre o Nordeste: 
Preservação do Patrimônio Histórico e Artístico, realizado em parceria pelo MEC e a Universidade Federal da Bahia, em Salvador. Arquivo Central do Iphan em Brasília: Programa de Cidades Históricas: Caixa 82, camisa 61G.

41. Seplan/PR: Secretaria de Planejamento da Presidência da República, antigo Miniplan (Ministério do Planejamento e Coordenação Geral).

42. Cf. Ministério do Planejamento e Coordenação Geral (1975, p. 19).

43. Cf. Secretaria de Planejamento da Presidência da República (1976, p. 2). propostos pelos estados para os monumentos a serem recuperados. Segundo Telles, eram definidos isoladamente, por conta de disponibilidade momentânea ou mesmo por interesses pessoais. Para ele, dever-se-ia levar em conta não apenas a rentabilidade econômica, a viabilidade de desenvolvimento, os programas de infraestrutura turística, social e cultural, mas também as características arquitetônicas, paisagísticas e plásticas de cada monumento e do sítio. Para isso, propunha a elaboração de planos para cada conjunto ou núcleo urbano, nos quais deveriam ser estudados, de forma conjunta, os usos a serem destinados aos monumentos. Silva Telles criticou ainda o fato de o programa priorizar cidades que já tinham infraestrutura turística, enquanto as que mais correriam riscos seriam afastadas das capitais, com maiores carências de estrutura turística e, portanto, sem previsão de investimentos.

Por outro lado, a própria Delegacia Regional da Seplan/PR 41 sugeriu ajustes no programa, em seguidos relatórios de avaliação desde agosto de 1974, como a necessidade de "critérios de prioridade mais racionais". A delegacia também demonstrava preocupação com a falta de condições do Iphan para acompanhar a execução das obras "sob os aspectos físicos e arquitetônicos".

Em um dos relatórios, a Delegacia Regional da Seplan/PR, indicava a falta de estrutura das entidades locais executoras e a pouca importância dada pelos governos estaduais ao programa, em detrimento a outros investimentos federais. $\bigcirc$ não atendimento a projetos de "conjuntos arquitetônicos, formadores da ambiência urbana" e "para o atendimento emergencial a edificações em perigo imediato ou estado de arruinamento que não se encontram sob a proteção direta do Iphan"42, bem como a inexistência de legislação específica para a proteção do patrimônio cultural na maioria dos estados, a falta de inventários de bens móveis e imóveis, a insuficiência de recursos financeiros e humanos para a conservação e melhoria de acervos, foram outros problemas levantados pela delegacia.

Em 1975, os textos dos documentos operativos do programa apresentam uma alteração nos conceitos: defende-se a "valorização ambiental urbana" e recomenda-se a elaboração de "planos plurianuais de restauração e valorização de monumentos e conjuntos de monumentos", o que possibilitaria uma análise integral das propostas para os sítios. Propõe-se a ampliação da possibilidade de investimento para áreas urbanas e obras emergenciais protegidas em qualquer nível da administração pública, desde que houvesse legislação específica de proteção e mecanismos que garantissem a manutenção dos bens restaurados. Isso pode ser entendido como a apropriação do patrimônio local como parte da política federal de preservação do patrimônio cultural brasileiro. Ademais, significou a indução à criação de legislação local, já que se viabilizava o investimento federal.

Os planos plurianuais de preservação estaduais" começaram a ser exigidos ainda em 1975, com o objetivo de prever o montante necessário para estender o Programa até 1979, o que foi concretizado pela Exposição de Motivos 060, de 09/04/76. Em outubro de 1976, outro relatório de avaliação ${ }^{43}$ da 
Delegacia Regional da Seplan/PR insere a "restauração integrada" como premissa do programa, que deveria ser "baseado no soerguimento econômico, social e físico dos sítios históricos, proporcionando bem-estar social e a consequente salvaguarda dos valores culturais").

Apesar das críticas que geraram ajustes no programa, sua execução teve grande visibilidade política. Iniciaram-se, nesse sentido, pressões de políticos mineiros para ampliação da área de atuação do PCH, propondo-se, inicialmente, expandir para os estados de Minas Gerais e Rio de Janeiro. Chamado para elaborar essa proposta, o economista Henrique Oswaldo de Andrade entendia ser adequada a inclusão de outros estados da federação ${ }^{44}$.

Novo grupo de trabalho interministerial ${ }^{45}$ foi constituído em junho de 1975, "para elaborar Programa Integrado de Reconstrução das Cidades Históricas do Espírito Santo, de Minas Gerais e do Rio de Janeiro" 46. Para a construção dessa ampliação, Henrique Oswaldo propôs um trabalho conjunto com os estados a serem contemplados, que deveriam apresentar e discutir com o GT os "programas de recuperação e preservação do patrimônio histórico e artístico estadual". Os estados, portanto, seriam chamados a opinar no momento da elaboração do programa, ou seja, na construção da política, ampliando seu papel antes restrito à apresentação de projetos a partir de critérios estabelecidos pela União.

Foram realizadas quatro reuniões, a partir de julho de 1975, sendo a primeira em Brasília e as demais em cada estado a ser contemplado na ampliação. Nas discussões do GT, consubstanciadas em atas de reunião, observa-se a busca de envolvimento de outras instituições no programa e do cumprimento do Compromisso de Brasília relativo à criação de entidades estaduais e municipais de preservação do patrimônio cultural.

Os resultados das atividades foram consubstanciados em relatório ${ }^{47}$, explicitando-se a intenção em induzir os estados e municípios à elaboração de políticas permanentes de presevação do patrimônio cultural. Do ponto de vista operacional, a grande mudança se referiu à constituição de uma Comissão de Coordenação e Acompanhamento (CCA), composta por Iphan, Embratur, Comissão Nacional de Regiões Metropolitanas e Política Urbana (CNPU) e Seplan. A composição da CCA avançou na intersetoralidade, mas não superou a centralidade da União ao não incluir os estados na estrutura decisória do programa. Outra alteração no programa reforçou o poder federal ao permitir que Iphan e Seplan pudessem indicar projetos diretamente, sem, necessariamente, ter de articular com os estados e municípios sua inserção nos planos estaduais.

Por outro lado, passam a ser financiáveis obras com vistas à recuperação de "expressões arquitetônicas locais ou regionais, independentemente da qualidade que thes possa ser atribuída" e, especialmente, "os exemplares caracterizadores socioculturais locais e/ ou regionais", reconhecendo a importância do patrimônio local.

A CCA teria atuação para as duas áreas-programa (Nordeste e Minas Gerais, Rio de Janeiro e Espírito Santol, aprovando os planos de preservação estaduais como primeira condição para os investimentos federais. Com isso se
44. Henrique Oswaldo de Andrade (1975) propôs três alternativas para ampliação do programa: a) Minas Gerais, Espírito Santo e Rio de Janeiro; b) Minas Gerais, Espírito Santo, Rio de Janeiro, São Paulo, Mato Grosso e Goiás; e c) todo o território nacional.

45. Portaria Interministerial MEC/SEPLAN/MIC 068/75. Ainda no mês de junho, os ministérios indicaram os representantes no GT: Augusto da Silva Telles (MEC/Iphan), Francisco Manoel de Mello Franco (MIC/Embratur) e Briane Elizabeth Panitz Bicca (Minter/ CNPU), além dos membros da Seplan/PR: Vicente da Costa Silva, Hélvio Polito Lopes e Henrique Oswaldo de Andrade, e do assessoramento do historiador Luiz Gonzaga Teixeira.

46. Não encontramos documentação do porquê restringirem apenas aos três estados. Entretanto, Henrique Oswaldo de Andrade esclareceu, em entrevista, que Minas Gerais havia pressionado politicamente por essa expansão desde o lançamento do programa, e que Élcio Costa Couto teria sugerido incluir o Rio de Janeiro. Andrade, por outro lado, teria proposto o Espírito Santo "para não ficar um buraco" entre as duas áreas-programa. Entrevista concedida pelo coordenador nacional do Programa de Cidades Históricas de 1975 a 1985 Henrique Oswaldo de Andrade, a Sandra Corrêa em 06/07/2012.

47. Ver Secretaria de Planejamento da Presidência da República, 1975. 
48. Ver Secretaria de Planejamento da Presidência da República (1977a). A EM foi regulamentada pela Portaria Interministerial Seplan/MEC/MIC 019, de 04 de março de 1977 , a partir das recomendações do relatório elaborado pelo grupo de trabalho.

49. Cf. Marcia Sant'anna (1995, p. 168).

50. Cf. Secretaria de Planejamento da Presidência da República (1977b, p. 1). pretendia analisar a coerência de roteiros turísticos propostos, além de garantir um planejamento global para todos os projetos, o que permitiria uma análise mais acurada sobre a potencial recuperação do sítio, e não apenas de monumentos isolados. Apenas após essa aprovação, os projetos deveriam ser encaminhados para exame do Iphan, da Embratur e da Seplan/PR. A EM 024/7748, de fevereiro de 1977, oficializou a proposta do grupo de trabalho. Segundo Sant'Anna:

O texto da EM n 024 já indica uma inflexão na política de financiamento do programa. Diminui sensivelmente a ênfase no desenvolvimento do turismo e estabelece novos critérios para a seleção de projetos, mais de acordo com as diretrizes da política de preservação das áreas urbanas iniciada em 1967 com apoio da UNESCO ${ }^{49}$.

Dessa forma, o discurso presente nos documentos do PCH aborda a problemática do patrimônio cultural a partir de um diagnóstico da situação urbana. Se, na EM 076-B/73, importava a possibilidade de uso imediato para o turismo, considerando a existência da infraestrutura turística, agora, na Portaria Interministerial Seplan/MEC/MIC 0 19/77, inserem-se também critérios relativos à situação de preservação e conservação do núcleo e ao seu desenvolvimento urbano:

a) em desagregação ou empobrecimento e que por suas características possam vir a se constituir em receptoras de fluxos turísticos;

b) com atividades turísticas consolidadas ou em vias de consolidação;

c) atingidas ou em vias de serem atingidas por obras ou atividades que por sua dinâmica possam representar perigo à preservação dos bens culturais; e

d) em processo de crescimento urbano acelerado 50 .

A viabilidade econômica de cada um dos monumentos a serem recuperados é relativizada para dar lugar à análise de seu papel para reorganização do espaço intraurbano, apresentando-se como possibilidade de usos com retorno social, articulando-se, nesse sentido, às diretrizes da primeira Política Nacional de Desenvolvimento Urbano brasileira, elaborada em 1975.

Entretanto, tal fato não significa uma mudança imediata na prática do $\mathrm{PCH}$. As reuniões da Comissão de Coordenação e Acompanhamento apresentam um processo lento de transformação das concepções para sua articulação com os problemas urbanos das cidades. Os relatos das reuniões informam, por exemplo, sobre a abordagem de Silva Telles, que parece ainda se restringir ao caráter da excepcionalidade e de aspectos estilístico e artístico de cada arquitetura como critérios para recomendar a aprovação de projetos.

Esses avanços, no entanto, vão sendo concretizados nos documentos oficiais do programa, aprovados previamente pela CCA, e que orientavam e direcionavam a elaboração dos projetos pelos estados. É o caso do documento Programa de Cidades Históricas: 1978. Na sua introdução, é abordado o processo de transformação social que o país vivia, do qual a urbanização seria uma das principais características. A situação das cidades históricas é analisada 
referindo-se às diretrizes contidas na Política de Desenvolvimento Urbano (PNDU - 1975): os problemas a serem enfrentados são entendidos como urbanos e o que se busca é a melhoria das condições de vida da população, levando-se em consideração a preservação do patrimônio cultural, e "contemplando com adequada ênfase os aspectos sociais e econômicos de seu desenvolvimento". Ou seja, persegue-se um melhor equilíbrio entre os diversos fatores que podem levar ao desenvolvimento urbano desses locais. A partir desse documento, uso recebe o adjetivo social. Com isso, parece-nos que, finalmente, o enfoque foi alterado de "conjunto de monumentos" para "conjunto urbano".

No mesmo documento, é ressaltada a mudança de conceitos ao longo do programa, que exigiria nova estratégia de atuação: "problemática esta que exige intervenções desde a infraestrutura urbana até medidas de legislação urbana específica para os mesmos". Também são informados os próximos passos a serem dados: a ampliação para todo o território nacional, bem como a adição de itens financiáveis para atender à "evolução" do conceito do patrimônio urbano $^{51}$.

Com isso, ainda no ano de 1978, a Seplan/PR iniciou negociação com o Banco Interamericano de Desenvolvimento (BID) com o objetivo de consignar recursos para a ampliação do $\mathrm{PCH}$. A proposta do governo brasileiro é criticada pelo banco, que recomenda restringir as ações do projeto, o que é contestado pela Secretaria Geral de Planejamento52: a exclusão de determinados itens comprometeria o "tratamento global do assunto". Assim, o secretário informa sobre a suspensão dos trabalhos decorrentes da negociação até que o banco aceitasse, inteiramente, os termos propostos pelo governo brasileiro.

Ofício de 08 de março de 1979, de João Paulo dos Reis Velloso, informa que "o mencionado Programa evoluiu para se transformar no Projeto de Revitalização Urbana de Núcleos Históricos" 53 (o futuro PRNH, que teve seu único projeto piloto implantado na cidade de Olinda, a partir de 1982). Ao mesmo tempo, o ministro emite a Exposição de Motivos 065/79, solicitando a complementação de recursos para o PCH. A mudança de ministros da Secretaria de Planejamento no mesmo mês encerra a negociação com o BID 54 .

Ao mesmo tempo, iniciou-se a mais profunda alteração de estrutura pela qual o Iphan já tinha passado, e que teria consequências para o PCH. A proposta de reestruturação do Iphan, elaborada pela Secretaria de Modernização e Reforma Administrativa (Semor/Seplan) com recursos do PCH, foi finalizada em novembro de 1979. O Iphan incorporou o Centro Nacional de Referências Culturais e o Programa de Cidades Históricas, e transformou-se em duas instituições: a Secretaria de Patrimônio Histórico e Artístico Nacional (Sphan) e a Fundação Nacional pró-Memória (FNpM) 55 - o chamado "sistema" Sphan/próMemória.

A incorporação do $\mathrm{PCH}$ a algum órgão federal fazia parte das diretrizes do novo governo, como esclarece a Exposição de Motivos 320, de novembro de 1979, assinada por Eduardo Portella e Antônio Delfim Netto ${ }^{56}$, que
51. Ver Secretaria de Planejamento da Presidência da República (1978, p.4-59 passim).

52. Ver Élcio Costa Couto, (1978).

53. Cf. João Paulo Reis Velloso (1979).

54. Em 15 de março, Mário Henrique Simonsen assume a Secretaria de Planejamento da Presidência da República, Antônio Delfim Netto, o Ministério da Fazenda, e Eduardo Portella toma posse no Ministério da Educação e Cultura. Segundo Henrique Oswaldo de Andrade, em entrevista concedida a Lia Calabre e Lúcia Lippi, em 07/04/2008, apesar de o projeto ter sido finalmente aprovado pelo banco, Delfim Netto decidiu utilizar, exclusivamente, recursos nacionais.

55. A secretaria manteve as atribuições e poderes legais do Iphan, especialmente o poder de polícia, e a Fundação Nacional próMemória (FNpM) era seu braço executivo e ao qual foi incorporado, portanto, o PCH.

56. Mário Henrique Simonsen é substituído por Golbery do Couto e Silva em 10/08/1979. Em 15/08/79, Antônio Delfim Netto assume a Seplan/PR. 
57. Quando da transferência, ainda não havia se efetivado a transformação do Iphan.

58. Importa esclarecer que a Fundação Nacional próMemória organizava suas ações em projetos e programas - nesse sentido, havia, na estrutura da FNpM, o Programa de Cidades Históricas, que, para além do PRNH, configurou-se como continuidade do programa da década de 1970, agora estendendo-o a todo território nacional.

59. Apesar do acompanhamento rigoroso realizado pela coordenação do programa, houve uma certa dificuldade para sistematizar os dados presentes nos diversos relatórios, que apresentavam algumas incoerências. Acreditamos que isso possa ter ocorrido pela diferença entre as datas previstas e, realmente, efetivadas para conclusão das obras ou pelo cancelamento, substituição e alteração de projetos já aprovados. Outro fator importante é que, de 1973 a 1979, o Brasil já vivia sob forte inflação (em 1973, a taxa girava em torno de $20 \%$ ao ano, segundo dados da FGV e Dieese), o que poderia explicar a diferença de valores para os mesmos projetos, ano a ano. Entretanto, nenhum fator de correção é explicitado pelos relatórios. A dificuldade ainda aumenta a partir de 1977 , pois as planilhas referentes a o acompanhamento dos projetos dos estados do Rio de Janeiro, Minas Gerais e Espírito Santo são bem menos detalhadas do que os documentos referentes ao Nordeste e, por isso, há vários projetos sem informações completas. A metodologia de pesquisa, indicação e resumo dos documentos pesquisados podem ser consultados em Sandra Rafaela Magalhães Corrêa (2012).

60. Foi utilizada a cotação transferiu o Programa de Cidades Históricas para o Iphan $^{57}$ e estendeu-o a todo território nacional. Nesse documento, foi consolidado o que já vinha sendo apresentado nos documentos internos do programa e no projeto elaborado para o BID: tratava-se agora de um projeto de desenvolvimento urbano dos núcleos históricos. O objeto (patrimônio cultural brasileiro) e o objetivo geral (identificar, documentar, proteger, classificar, restaurar e revitalizar esse patrimônio) são ampliados. Os objetivos específicos estabelecem um "melhor conhecimento, maior participação e o uso adequado desses bens".

Assim, plenamente integrado ao sistema que definia a política de preservação do patrimônio cultural brasileiro, o PCH entrou numa fase em que se constituía em uma ação dessa políitica, e não mais em um programa específico ${ }^{58}$, utilizando abordagens e instrumentos bastante diferenciados com relação ao período até 1979. No entanto, isso não impediu que essa nova fase fosse considerada pelo próprio Iphan como continuidade do programa, apesar de, em nossa análise, dever ser entendida como um resultado das atividades que se encerraram na fase anterior.

Resultados do programa: projetos financiados e recursos investidos

Os projetos aqui analisados foram os aprovados até 197959 (antes da incorporação do programa ao (phan), mesmo que sua conclusão tenha sido posterior a essa data. Para a análise, consideramos apenas os recursos da Seplan provenientes do Fundo de Desenvolvimento de Programas Integrados (FDPI), iá que não há na documentação controle sobre os investimentos realizados pelo Iphan no período, apesar de no programa ser destacado orçamento específico para o órgão. Ademais, alguns valores globais foram convertidos em dólares americanos ${ }^{60}$, visando a minimizar as distorções decorrentes da alta taxa de inflação do período.

As análises possuem, predominantemente, três focos:

a) a distribuição dos recursos por região e estado, considerando os investimentos de contrapartida dos estados, buscando verificar o equilíbrio de investimentos relacionando-os ao objetivo de desenvolvimento regional;

b) o custo dos projetos por estado, buscando verificar seu perfil de execução, também visando avaliar o objetivo de desenvolvimento regional;

c) a distribuição dos recursos e de quantidade de projetos por tipo, buscando verificar o perfil de investimentos do programa, considerando as alterações conceituais ocorridas.

Iniciaremos a análise pelas previsões de recursos constantes nas Exposições de Motivos 076-B/73, 060/76, 024/77 e 065/79, nas quais se verifica um montante total de recursos de 575 milhões de cruzeiros. 
Quadro 1: Previsão de recursos constantes nas Exposições de Motivos, em milhões de cruzeiros.

\begin{tabular}{|c|c|c|c|c|c|}
\hline & $\begin{array}{c}\text { EM 076-B } \\
\text { (Nordeste) }\end{array}$ & $\begin{array}{c}\text { EM 060/76 } \\
\text { (Nordeste) }\end{array}$ & $\begin{array}{c}\text { EM 024/77 } \\
\text { (MG, RJ e ES) }\end{array}$ & $\begin{array}{c}\text { EM 065/79 } \\
\text { (Nordeste e MG, } \\
\text { R e ES 50) }\end{array}$ & TOTAL \\
\hline 1973 & 10 & - & - & - & 10 \\
\hline 1974 & 20 & - & - & - & 20 \\
\hline 1975 & 20 & - & - & - & 20 \\
\hline 1976 & 20 & 40 & - & - & 60 \\
\hline 1977 & 20 & 55 & 90 & - & 165 \\
\hline 1978 & - & 60 & 100 & - & 160 \\
\hline 1979 & - & 70 & - & $70^{*}$ & 140 \\
\hline TOTAL & 90 & 225 & 190 & 70 & 575 \\
\hline
\end{tabular}

* Cr\$ 50 milhões aos estados do Nordeste e 20 milhões para Rio de Janeiro, Minas Gerais e Espírito Santo.

Ao analisar esses dados, observa-se uma desigualdade na destinação de recursos realizada para o Nordeste com relação ao destinado aos estados de Minas Gerais, Rio de Janeiro e Espírito Santo. Os quadros abaixo informam os valores totais:

Quadro 2: Valores totais previstos nas Exposições de Motivos 076-B/73, 060/76, 024/77 e 065/79, em milhões de dólares americanos.

\begin{tabular}{|c|c|c|c|c|}
\hline Em U\$ (em milhões) & TOTAL & VALOR/ANO & $\begin{array}{c}\text { VALOR POR } \\
\text { ESTADO }\end{array}$ & $\begin{array}{c}\text { VALOR ANUAL } \\
\text { POR ESTADO }\end{array}$ \\
\hline NORDESTE & 15,65 & 2,24 & 1,74 & 0,25 \\
\hline MG, RJ e ES & 12,50 & 4,17 & 4,17 & 1,39 \\
\hline
\end{tabular}

Escolhemos como indicador para análise os valores correspondentes ao destinado por estado e por ano, porque as áreas-programas tiveram períodos diferentes (sete anos para o Nordeste e três para o Sudeste) e também cada região possui um número diverso de estados (nove e três, respectivamente). Assim, temos que os valores destinados ao Nordeste, considerando o indicador "valor anual por estado", representam cerca de 9\% em cruzeiros, ou 15\% em dólares, com relação aos direcionados para os estados de Minas Gerais, Rio de Janeiro e Espírito Santo.

$\bigcirc$ resultado dessa análise parece ser incoerente com os objetivos do programa, ainda mais se observarmos que sua ampliação para a região Sudeste ocorreu a partir do momento em que o PCH aproximou-se da política de desenvolvimento urbano, que, entre outros objetivos, visava à desconcentração urbana e ao equilíbrio do desenvolvimento econômico social entre as diversas cidades brasileiras. Analisando sob o ponto de vista da Política Nacional de Desenvolvimento Urbano, as regiões metropolitanas de São Paulo e do Rio de Janeiro são "consideradas como as principais responsáveis pela aceleração dos desequilíbrios regionais", e deveria ser desestimulada "a implantação de uma série de atividades, tanto restringindo o uso do solo como reduzindo alguns investimentos de serviços e infraestrutura"bl. constante em dezembro do ano em que foi mencionado o recurso.

61. Cf. Jorge Guilherme Francisconi; Maria Adélia Souza (1975, p. 67). 
62. Ibid.(p. 71)

63. Cr\$ 735.519.971,00. Convertendo os valores totais de cada ano para o dólar americano, utilizandose a cotação de dezembro, temos o valor total de $\mathrm{U} \$$ 17.752.079,15. Para os valores cujos projetos não tinham informações sobre a data de sua conclusão, usouse o quantitativo constante em dezembro de 1979.
A PNDU coloca no mesmo "subsistema" - de promoção - as cidades antigas mineiras e as do litoral do Nordeste, bem como as áreas "que foram prósperas em função do apogeu econômico no passado", vinculadas aos ciclos do café, da mineração e da cana de açúcar (que incluiriam a região Sudeste). Assim, verifica-se que a política urbana diferenciou as regiões Sudeste e Nordeste com relação às suas capitais, mas entendeu que as cidades com potencial turístico que apresentavam sinais de estagnação ou decadência econômica, independente de onde se localizavam, deveriam receber investimentos para sua "promoção". Contudo, a PNDU ressalta que "a manipulação dessas cinco áreas é extremamente diferenciada, face ao tipo de alternativa que se pretenda adotar para a implementação da política de desenvolvimento urbano"62. Entretanto, tal "subsistema de promoção", diferentemente de outros, não teve proposta de intervenção explicitada na PNDU. Por outro lado, o Programa de Cidades Históricas não diferenciou as capitais e regiões metropolitanas das pequenas cidades mineiras e fluminenses, não aplicando, portanto, os subsistemas propostos pela PNDU.

Nossa análise não busca julgar a necessidade ou não das cidades históricas de Minas Gerais, Rio de Janeiro e Espírito Santo receberem recursos, mas sim o impacto dos investimentos sob o aspecto do desenvolvimento regional - objetivo claramente explicitado nos momentos iniciais do programa. Nesse sentido, podemos afirmar que o PCH, efefivamente, atuou para cumprito apenas até 1977, pois apesar da quantidade considerável de recursos alocados para o patrimônio cultural do Nordeste, talvez sem precedentes, a estratégia de desconcentração relacionada à proposta inicial de desenvolvimento dessa área foi, praticamente, anulada quando da entrada dos três estados do Sudeste, que receberam investimentos superiores, em três anos, aos destinados à outra região durante sete anos.

Com relação aos valores efetivamente investidos temos, até 1982 . considerando os projetos aprovados até 1979 -, o total de $\operatorname{Cr} \$ 735$ milhões ${ }^{63}$. Continuando a análise, agora com relação aos investimentos realizados em cada região, mantendo-se o indicador "valor anual por estado", a representatividade do Nordeste melhora quase 100\%, com 15\% nos valores em cruzeiros (ver Quadro 3). Entretanto, é ainda bastante desigual, mantendo-se a conclusão de que os estados da região Sudeste receberam, significativamente, mais recursos que os do Nordeste.

Quadro 3: Valores investidos efetivamente de 1973 a 1983 nos projetos aprovados até 1979.

\begin{tabular}{|c|c|c|c|c|}
\hline Em Cr\$ & TOTAL & VALOR/ANO & $\begin{array}{c}\text { VALOR POR } \\
\text { ESTADO }\end{array}$ & $\begin{array}{c}\text { VALOR ANUAL POR } \\
\text { ESTADO }\end{array}$ \\
\hline NORDESTE & $396.562 .992,16$ & $56.651 .856,02$ & $44.062 .554,68$ & $6.294 .650,67$ \\
\hline MG, RJ e ES & $338.956 .979,00$ & $112.985 .659,67$ & $112.985 .659,67$ & $37.661 .886,56$ \\
\hline
\end{tabular}

Com relação à distribuição intrarregional dos recursos, no que se refere ao Sudeste, verifica-se que o Espírito Santo concluiu apenas um projeto e utilizou Cr \$ 6 milhões do FDPI, o que configura uma concentração de investimentos ainda mais evidente nos estados que, tradicionalmente, recebiam recursos do governo federal 
- Minas Gerais e Rio de Janeiro. Já o Nordeste apresenta mais equilíbrio, percebendose, no entanto, uma diferença significativa apresentada pela Bahia e Pernambuco: enquanto esses captaram em torno de 15\% do investimento, os estados de Alagoas, Ceará, Piauí, Paraíba, Rio Grande do Norte receberam cerca de 2\% a 3\% dos recursos e Sergipe e Maranhão, aproximadamente, 5\%. Importante lembrar que a Bahia já tinha projetos em andamento para recuperação do Pelourinho, em Salvador, antes do programa, e que Pernambuco sediava a Delegacia Regional da Seplan/ PR. Ambas as situações, provavelmente, facilitaram o andamento do programa nessas duas localidades. Ademais, Pernambuco e Bahia, tradicionalmente, entre os estados do Nordeste, iá recebiam maiores atenções do lphan.

Quadro 4: Valores investidos por fonte e estado, em Cr\$ (milhões)

\begin{tabular}{|c|c|c|c|c|c|}
\hline Estado & Seplan & Contrapartida & $\begin{array}{c}\% \\
\text { (contrapartida/ } \\
\text { total) }\end{array}$ & Total & $\begin{array}{c}\% \\
\text { (total Estado/ } \\
\text { total Programa) }\end{array}$ \\
\hline ALAGOAS & 12.350 .333 & 3.159 .958 & 20,37 & 15.510 .291 & 2,11 \\
\hline BAHIA & 92.051 .325 & 24.063 .888 & 20,72 & 116.115 .213 & 15,79 \\
\hline CEARÁ & 8.954 .621 & 2.237 .420 & 19,99 & 11.192 .041 & 1,52 \\
\hline ESPÍRITO SANTO & 6.000 .000 & 1.200 .000 & 16,67 & 7.200 .000 & 0,98 \\
\hline MARANHÃO & 34.473 .272 & 8.639 .530 & 20,04 & 43.112 .802 & 5,86 \\
\hline MINAS GERAIS & 84.758 .335 & 40.790 .129 & 32,49 & 125.548 .464 & 17,07 \\
\hline PARAÍBA & 19.894 .615 & 4.973 .654 & 20,00 & 24.868 .268 & 3,38 \\
\hline PERNAMBUCO & 86.693 .176 & 22.182 .848 & 20,37 & 108.876 .024 & 14,80 \\
\hline PIAUÍ & 14.518 .718 & 3.629 .680 & 20,00 & 18.148 .398 & 2,47 \\
\hline RIO DE JANEIRO & 97.678 .200 & 108.530 .315 & 52,63 & 206.208 .515 & 28,04 \\
\hline RIO GRANDE & 17.007 .666 & 4.250 .615 & 20,00 & 21.258 .281 & 2,89 \\
DO NORTE & & & & & 37.481 .674 \\
\hline SERGIPE & 29.721 .604 & 7.760 .070 & 20,70 & 5,10 \\
\hline Total Geral & 504.101 .865 & 231.418 .106 & & 735.519 .971 & 100 \\
\hline
\end{tabular}

Gráfico 1: Valores investidos por fonte e estado, em Cr\$ (milhões)

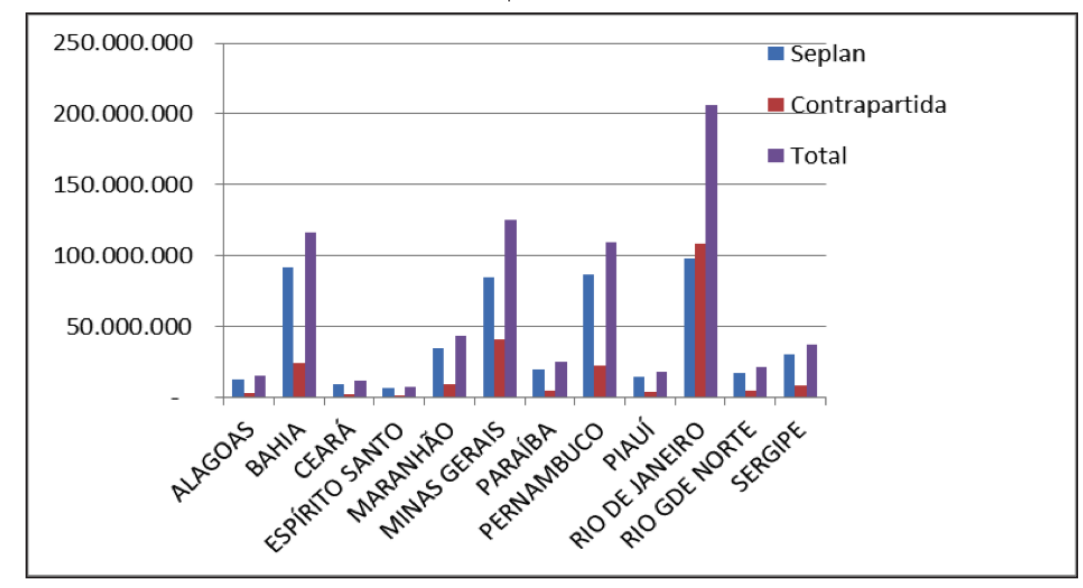


Ainda com relação à distribuição dos recursos, importa verificarmos os investimentos estaduais referentes às contrapartidas, lembrando que a partir de 1977 os projetos propostos pelo Iphan e Seplan dispensariam a parcela estadual. Em termos de recursos, verifica-se que a maioria ficou em $20 \%$, conforme estabelecia - programa lpequenas diferenças para mais ou para menos podem ser imputadas à imprecisão dos dados). Poder-se-ia inferir que o Rio de Janeiro, que investiu cerca de 50\%, e Minas Gerais, 30\%, tiveram maior interesse pelo programa. Essas cifras tomam outra perspectiva quando é analisado o número de projetos executados sem apresentação de contrapartida. Rio de Janeiro destaca-se com mais de $30 \%$, seguido da Bahia e de Pernambuco, com 14,81\% e 12\% respectivamente, além de Minas Gerais, com 5,88\%, considerando o número de projetos. Os demais estados não tiveram projetos com dispensa de contrapartida. Esse quadro demonstra as preferências do Iphan, pois apenas ele e a Seplan poderiam propor ações com $100 \%$ de recursos do FDPI, e relativiza o interesse do Rio de Janeiro sugerido pela contrapartida maior oferecida.

Quadro 5: Número de projetos que dispensaram contrapartida (100\% dos recursos FDPI)

\begin{tabular}{|c|c|c|c|c|}
\hline \multirow{2}{*}{ ESTADO } & \multicolumn{4}{|c|}{ N PROJETOS $^{\circ}$} \\
\cline { 2 - 5 } & S/CONTRAPARTIDA & $\%$ & SI & TOTAL \\
\hline ALAGOAS & - & - & - & 6 \\
\hline BAHIA & 4 & 14,81 & - & 27 \\
\hline CEARÁ & - & - & - & 4 \\
\hline ESPÍRITO SANTO & - & - & - & 1 \\
\hline MARANHÃO & - & - & 4 & 14 \\
\hline & & & & \\
MINAS GERAIS & 2 & 5,88 & 11 & 34 \\
\hline PARAÍBA & - & - & - & 4 \\
\hline PERNAMBUCO & 3 & 12,00 & - & 25 \\
\hline PIAUÍ & - & - & - & 6 \\
\hline RIO DE JANEIRO & 5 & 33,33 & 3 & 15 \\
\hline RIO GRANDE DO & - & - & 4 & 14 \\
\hline NORTE & & & & 24 \\
\hline SERGIPE & - & - & 1 & 174 \\
\hline Total Geral & & & & \\
\hline
\end{tabular}

Vemos também uma diferença com relação aos tipos de projetos apresentados por Rio de Janeiro e Minas Gerais. $O$ primeiro tem a média de valor por projeto mais cara do $\mathrm{PCH}$, com quase $\mathrm{Cr} \$ 14$ milhões por iniciativa, enquanto a média foi de pouco mais de $\mathrm{Cr} \$ 4$ milhões/projeto. Minas Gerais tem um perfil bastante diversificado, investindo em cursos e planos. Parece-nos, portanto, que o interesse do Rio de Janeiro vinculava-se a uma visibilidade política imediata, enquanto Minas Gerais se coadunava com o conceito do programa na busca do desenvolvimento urbano de suas cidades históricas. 
Gráfico 2: Média de investimento/projeto, por estado.

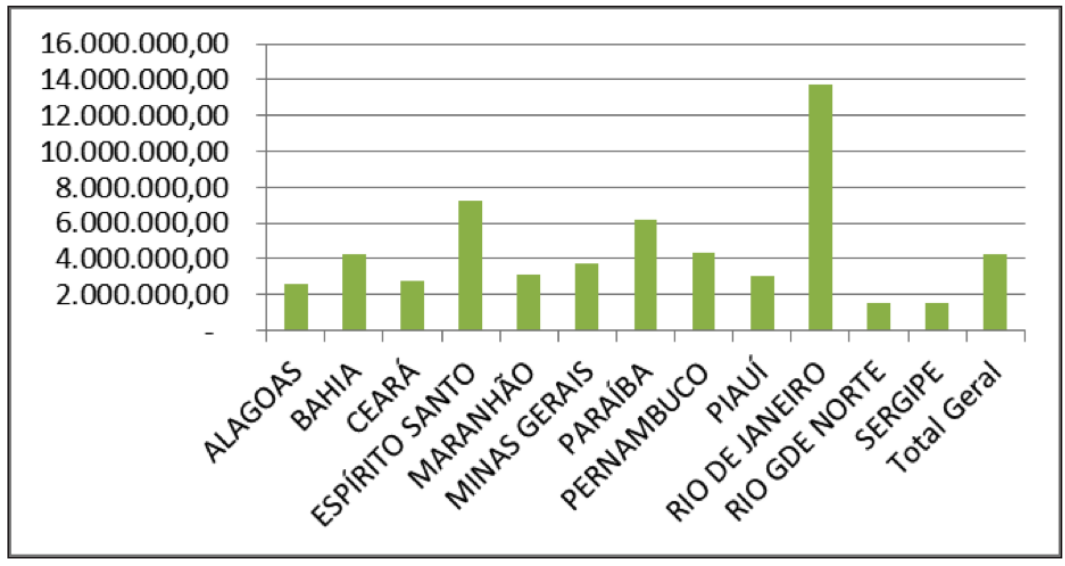

No que se refere a tipos de projetos propostos pelos estados, temos uma maioria de obras em monumentos, representando quase $85 \%$ dos investimentos.

Quadro 6: Valores investidos por tipos de projetos, por estado.

\begin{tabular}{|c|c|c|c|c|c|c|}
\hline Estado & Cursos & $\begin{array}{c}\text { Obras em } \\
\text { monumentos }\end{array}$ & $\begin{array}{c}\text { Planos } \\
\text { urbanos }\end{array}$ & $\begin{array}{c}\text { Obras } \\
\text { urbanas }\end{array}$ & Outros & Total Geral \\
\hline ALAGOAS & & 14.352 .291 & 1.158 .000 & & & 15.510 .291 \\
\hline BAHIA & & 104.481 .288 & 6.893 .000 & & 4.740 .925 & 116.115 .213 \\
\hline CEARÁ & & 11.192 .041 & & & & 11.192 .041 \\
\hline $\begin{array}{c}\text { ESPÍRITO } \\
\text { SANTO }\end{array}$ & & 7.200 .000 & & & & 7.200 .000 \\
\hline MARANHÃO & & 42.892 .047 & & & & \\
\hline MINAS GERAIS & 2.204 .000 & 63.109 .168 & 14.944 .709 & & 45.290 .587 & 125.548 .464 \\
\hline PARAÍBA & & 24.868 .268 & & & & 24.868 .268 \\
\hline PERNAMBUCO & 1.890 .000 & 89.218 .884 & & 3.350 .000 & 14.417 .140 & 108.876 .024 \\
\hline PIAUÍ & & 18.148 .398 & & & & 18.148 .398 \\
\hline $\begin{array}{c}\text { RIO DE } \\
\text { JANEIRO }\end{array}$ & & 190.412 .515 & & 15.796 .000 & & 206.208 .515 \\
\hline RIO GRANDE \\
DO NORTE
\end{tabular}

Alagoas, Bahia, Sergipe e Minas Gerais, com destaque para este último, investiram na elaboração de planos urbanísticos. Foram propostas obras em áreas urbanas ${ }^{64}$ pelos estados de Pernambuco, Rio de Janeiro e Sergipe. O campo "outros", nos gráficos e quadros, refere-se a documentários, inventários, pesquisas históricas e arqueológicas.
64. As obras urbanas, identificadas nos documentos do PCH como "agenciamento", tratavam-se de recuperação de praças, logradouros, pontes, orlas marítimas ou de rios etc. 
Gráfico 3: Número de tipos de projetos propostos por estado.

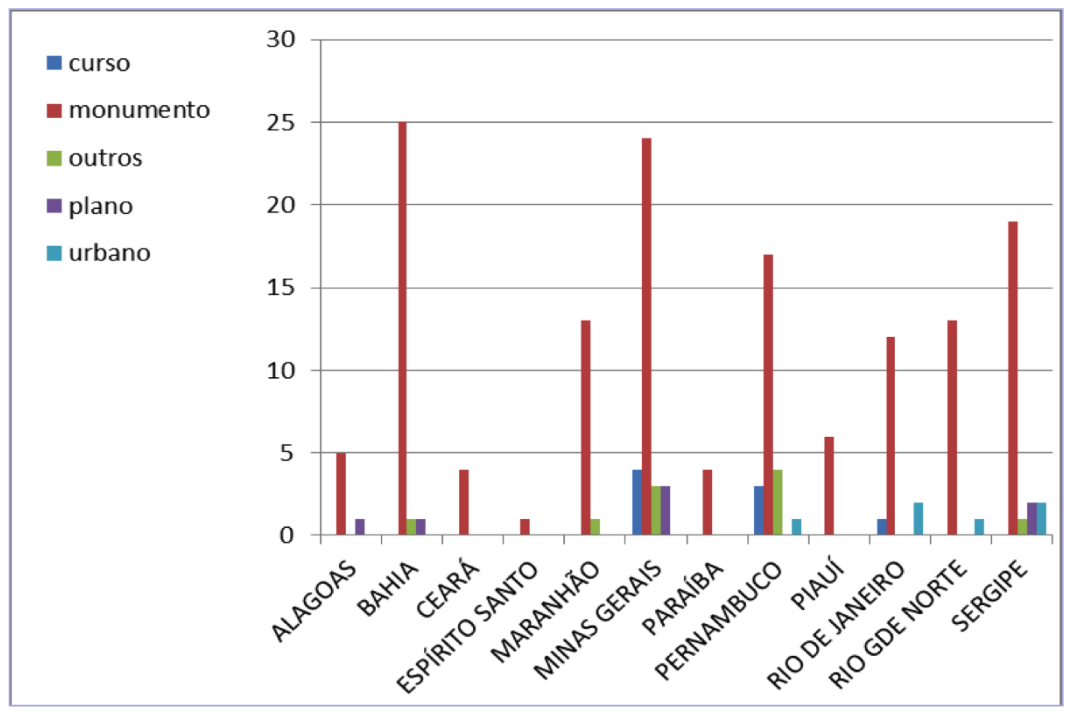

A verificação dos tipos de projeto por ano visa verificar se houve alteração no perfil de investimentos com relação à alteração conceitual dos documentos do programa observada de 1972 a 1979. Notamos que o planejamento integrado pretendido não foi absorvido pelos estados (talvez o que mais tenha se aproximado tenha sido Minas Gerais), não constituindo a recuperação dos núcleos urbanos ao investirem concentradamente em obras de restauração de edifícios, e quase nada em infraestrutura urbana. Também percebemos que é pouco significativo o investimento em áreas urbanas (planos e obras):

Quadro 7: Número de projetos por tipo

\begin{tabular}{|c|c|c|c|c|c|c|c|}
\hline Ano & Cursos & $\begin{array}{c}\text { Obras em } \\
\text { monumentos }\end{array}$ & $\begin{array}{c}\text { Planos } \\
\text { urbanos }\end{array}$ & $\begin{array}{c}\text { Obras em } \\
\text { áreas urbanas }\end{array}$ & Outros & $\begin{array}{c}\text { Total } \\
\text { Geral }\end{array}$ & $\%$ \\
\hline 1974 & & 1 & & & & 1 & 1 \\
\hline 1975 & 1 & 13 & & & & 14 & 8 \\
\hline 1976 & 2 & 10 & 1 & 1 & 3 & 17 & 10 \\
\hline 1977 & & 10 & & & & 10 & 6 \\
\hline 1978 & & 13 & & 1 & & 14 & 8 \\
\hline 1979 & & 5 & & & & 5 & 3 \\
\hline 1980 & 1 & 29 & 2 & 2 & 2 & 36 & 21 \\
\hline 1981 & & 19 & 1 & & 4 & 24 & 14 \\
\hline 1982 & & 4 & & & & 4 & 2 \\
\hline 1983 & & 2 & & & & 2 & 1 \\
\hline Sem informação & 4 & 37 & 3 & 2 & 1 & 47 & 27 \\
\hline Total Geral & 8 & 143 & 7 & 6 & 10 & 174 & 100 \\
\hline
\end{tabular}


Assim, a nosso ver os investimentos realizados pelo programa não acompanharam as diversas alterações conceituais propostas em sua concepção. Apesar de a intersetorialidade e a descentralização exigirem um tempo mais longo de consolidação de alterações conceituais, por ter de acomodar diversos interesses em jogo, acreditamos que a representação dos estados na CCA poderia ter encurtado o percurso entre a "teoria" e as práticas do PCH. No entanto, seu sucesso e sua visibilidade política viabilizariam a continuidade de suas ações na década de 1980:

(...) em fins de 1979 (...) a SPHAN/FNpM (...) considerou indispensável a integração das diversas esferas - federal, estadual e municipal - para implantação de programas e projetos nas cidades históricas (abrangendo as áreas de educação, saúde, transporte, habitação, trabalho). (...) De certo modo, o Programa de Cidades Históricas havia tirado do arruinamento vários edifícios tombados individualmente, conferindo-lhes novos usos. Mas nada ainda havia sido efetuado para o conjunto de edificações particulares que compunham os sítios históricos. O casario de Olinda necessitava de cuidados. $\bigcirc$ empobrecimento das famílias estava levando os imóveis ao arruinamento e provocando o esvaziamento ou a substituição de moradores ${ }^{65}$.

Isso indica, a nosso ver, que as sementes plantadas pela política implementada pelo PCH/Iphan na década de 1970 começaram a florescer em algumas cidades históricas brasileiras na década de 1980. Olinda é a mais emblemática, pois foi selecionada como Projeto Piloto para o Programa de Recuperação e Revitalização de Núcleos Históricos (PRNH) ${ }^{66}$, elaborado em continuidade ao $\mathrm{PCH}$, como vimos anteriormente:

O PRNH, iniciativa do Ministério da Educação e Cultura (SPHAN/Pró-Memória) e do Ministério do Interior (CNDU e BNH), teve o sítio histórico de Olinda como palco de uma experiência pioneira, com a ação experimental do Projeto Piloto Olinda - PPO, estruturado em metodologia participativa. Neste programa os moradores participaram das etapas da recuperação do patrimônio construído, que se encontrava bastante degradado. Numa ação complementar ao PCH (encerrado em 1980) [sic], o novo Programa viria suprir uma lacuna dos órgãos de proteção na recuperação do casario, de propriedade privada ${ }^{67}$.

PRNH caracterizava-se pela articulação da Fundação Nacional PróMemória com o Ministério de Desenvolvimento Urbano e o Banco Nacional de Habitação, em nível nacional, para ações que seriam implementadas com recursos do governo federal, em especial um financiamento para recuperação de imóveis de propriedade privada. Propunha, a nível local, a elaboração de um plano que integraria ações com investimentos nacionais e municipais, envolvendo a população local e extrapolando as intervenções nos imóveis, considerando fatores de desenvolvimento social para métodos e seleção das ações.

Nessa experiência, portanto, parece ser concretizada a integração proposta na concepção do programa, ainda em 1973, mas com significativo amadurecimento no que se refere ao entendimento da complexidade dos sítios históricos com relação aos seus problemas urbanos e sociais, como havia sido explicitado na Exposição de Motivos 024/77 e na Portaria Interministerial 019/77.
65. Cf. Fernanda Maria Buarque de Gusmão (2011, p. 92)

66. Lembramos que em ofício enviado ao presidente do BID, em 08 de março de 1973, para financiamento da continuidade do PCH, João Paulo dos Reis Velloso informa que o programa passaria a chamar-se Projeto de Revitalização Urbana dos Núcleos Históricos, muito parecido com o nome dado ao programa implementado a partir de 1980 em parceria com a Comissão Nacional de Desenvolvimento Urbano (CNDU).

67. Cf. Fernanda Maria Buarque de Gusmão (2011, p. 92). 
68. Cf. Ministério do Planejamento e Coordenação Geral, op. cit (1973, p. 4).

69. Manteve-se a definição "nível operário" utilizada na EM 076-B/73 e em todos os documentos do programa.

70. Cf. José Luiz Mota Menezes (2008, p. 82).
A execução descentralizada: padronização e medição de resultados e qualificação e estruturação das equipes locais

Para implementar a execução descentralizada do PCH, sua coordenação estabeleceu uma série de ações. Dessas, selecionamos três abordagens, entendendo que foram fundamentais para o sucesso da articulação com os estados: formação de recursos humanos, implantação de entidades estaduais e forma de administração do programa.

A preocupação com a formação e com a qualificação de recursos humanos para restauração e conservação de bens móveis e imóveis esteve presente desde o início do programa, já na Exposição de Motivos 076-B/73:

IV - A formação de recursos humanos para a restauração e preservação de monumentos e obras históricas ou artísticas, a nível universitário, a nível intermediário e operário.

$V$ - A formação de pessoal especializado na criação artística e artesanal. Esse pessoal complementará os trabalhos de restauração de monumentos e objetos artísticos, como também contribuirá com a atividade turística na oferta de artigos regionais ${ }^{68}$.

Essa necessidade é apontada também pelos relatórios elaborados pela Delegacia Regional da Seplan/PR, seguidamente atribuindo à falta de mão de obra especializada o atraso e a inviabilidade da elaboração de projetos, assim como da execução de obras em estados como Alagoas e Sergipe. Entendia-se que a formação de recursos humanos era necessária em dois níveis: operário e intermediário, para trabalhos nas obras de restauração, tanto para a construção civil como para restauração de obras de arte integradas aos monumentos; e universitário, para execução de projetos de restauração. Além disso, a Exposição de Motivos cita a necessidade de qualificar mão de obra para "criação artística e artesanal", visando a contribuir para a atividade turística "na oferta de artigos regionais". Apesar de haver uma proposta feita pelo Estado de Minas Gerais para treinamento de artesãos locais, essa última abordagem não foi enfatizada pelo programa, provavelmente por sua falta não gerar empecilhos para sua execução, ao contrário da qualificação para a restauração de monumentos.

No "nível operário"69, o programa financiou dois cursos para mestres de obras, realizados pela Fundação do Patrimônio Histórico e Artístico de Pernambuco (Fundarpe) nos anos de 1975 e 1976. Segundo Menezes, o Curso Intensivo de Preparação de Mestres de Obras em Conservação e Restauração de Monumentos Históricos foi:

Uma experiência baseada na maneira de ensinar das Escolas de Artes e Ofícios e voltada a suprir a carência de profissionais de interesse das obras de tal gênero então multiplicadas pelo Nordeste. Patrocinado pela Seplan/Iphan e executado pela Fundarpe, o curso teve êxito surpreendente. Para o curso, organizou-se uma série de aulas impressas para os alunos, um manual de execução à maneira daqueles editados na primeira metade do século em Portugal70. 
curso não foi institucionalizado e, portanto, não teve prosseguimento. Entretanto, outras iniciativas nesse sentido ocorreram na década de 1990, como as oficinas-escola de Salvador e João Pessoa. $\bigcirc$ Programa Monumenta, na década de 2000, buscou reeditar experiências similares, como os cursos Formação Básica em Restauro e Conservação e Qualificação de Mestres Artífices, inclusive financiando a ida de mestres para Veneza, na Itália.

Mais recentemente, no ano de 2011 , o curso realizado pelo PCH foi reeditado pelo Centro de Estudos Avançados de Conservação Integrada (CECI), sediado em Recife, Pernambuco. O Iphan e a experiência do Programa de Cidades Históricas foram citados na apresentação do curso:

Pernambuco tem experiência na qualificação de mestres de obras em conservação e restauro do patrimônio cultural construído desde 1974/75, quando a FUNDARPE e o IPHAN aplicaram o Curso Intensivo de Preparação de Mestres de Obras em Conservação e Restauração de Monumentos Históricos. Naquela ocasião estavam-se iniciando importantes obras nos Estados do Nordeste do Brasil pelo Programa de Cidades Históricas da SEPLAN-PR ${ }^{71}$.

Dessas ações, apenas as oficinas-escola oferecem vagas regularmente, e sua criação não pode ser vinculada ao Programa de Cidades Históricas. Nesse sentido, é possível afirmarmos que os cursos de "nível operário" não se institucionalizaram, a despeito da necessidade de qualificação desse tipo de mão de obra até os dias atuais.

Já no que se refere ao nível universitário, o programa teve frutos mais duradouros. Em 1974, o PCH financiou a participação de funcionários do Iphan e de entidades estaduais no Curso de Conservação e Restauro, realizado pela Faculdade de Arquitetura e Urbanismo da Universidade de São Paulo (FAU/USP) em parceria com o próprio Iphan e o Condephaat. Segundo Lowande, o curso teve como coordenadores os arquitetos Nestor Goulart dos Reis Filho (professor da FAU/ USP), Luís Saia (da Delegacia Regional do Iphan em São Paulo) e Ulpiano Bezerra de Menezes (FAU/USP). O autor opina que "os trabalhos que se referem a esse curso - apresentam como uma espécie de 'divisor de águas' dentro das práticas preservacionistas paulistas". Ainda de acordo com Lowande, "a realização desse curso atendia às recomendações dos compromissos de Brasília e Salvador, que mencionavam a realização de cursos de especialização na área de preservação e conservação e a realização de parcerias entre o IPHAN e as universidades"72.

Em 1976, o programa financiou integralmente, por meio de um convênio com o Centro de Artes, Arquitetura e Comunicação do Departamento de Arquitetura e Urbanismo da Universidade Federal de Pernambuco, nova experiência para formar arquitetos ou engenheiros, com duração de quatro meses. Segundo Henrique Oswaldo de Andrade, o curso de Pernambuco foi inspirado naquele realizado em São Paulo, cujo programa foi fornecido por Luís Saia. A exigência era de que os participantes fossem funcionários de entidades estaduais envolvidas na execução do programa. A proposta visava, além da qualificação profissional, superar um dos
71. Cf. Centro de Estudos Avançados de Conservação Integrada, 2011.

72. Cf. Walter Francisco Figueiredo Lowande (2010, p. 178). 
principais "gargalos" operacionais do PCH - a falta de bons projetos de intervenção: durante o curso, o profissional deveria desenvolver um anteprojeto para uma obra de restauração que fizesse parte do plano estadual apresentado e aprovado pelo programa. A entidade local que o indicou, por sua vez, deveria se comprometer com a garantia das condições para finalização do projeto executivo e dos complementares quando do retorno do profissional à entidade estadual. $\bigcirc$ programa, por fim, garantiria os recursos necessários à execução da obra de restauração.

A terceira edição do curso, se considerarmos a de São Paulo como a primeira, ocorreu em Minas Gerais, em 1978, com duração de seis meses. O quarto curso ocorreu em 1981, já sob convênio com o Centro de Estudos de Arquitetura da Bahia (CEAB), vinculado à Faculdade de Arquitetura e Urbanismo da Universidade Federal da Bahia, quando recebeu o nome de Curso de Especialização em Restauração e Conservação de Monumentos e Conjuntos Históricos (Cecre). A partir daí, passou a ser ofertado bianualmente até 2009, quando se tornou mestrado profissional. $\bigcirc$ curso recebe apoio do lphan até os dias atuais.

Além do Cecre, o Programa fomentou a criação e estruturação do Curso de Conservação e Restauração de Bens Culturais Móveis, que deu origem, em 1980, ao Centro de Conservação e Restauração de Bens Culturais Móveis (Cecor), onde se realizaram várias edições do curso, agregando laboratórios de análises especializadas. Segundo Henrique Oswaldo de Andrade, a ideia foi apresentada pela professora Beatriz Coelho, da Universidade Federal de Minas Gerais (UFMG), durante uma visita realizada por ele e por Héctor Arena (Unesco) a Belo Horizonte. Desde o início vinculado à Escola de Belas Artes da UFMG, o Cecor passou recentemente por uma reestruturação, sendo transformado em graduação de nível superior.

Ambos os cursos são considerados pela Unesco referência na América Latina para conservação e restauração. As reestruturações que vêm sofrendo refletem as mudanças ocorridas nos últimos anos na política de pós-graduação do MEC, ao reduzir as cargas horárias de especialização, e também o mercado de trabalho da área, que vem se ampliando significativamente na última década.

Quadro 8: Profissionais qualificados em cursos realizados pelo Programa de Cidades Históricas.

\begin{tabular}{|c|c|c|c|c|c|c|c|}
\hline \multirow{2}{*}{$\begin{array}{c}\text { ANOS/ } \\
\text { CURSOS }\end{array}$} & \multicolumn{2}{|c|}{ ARQUITETOS/ENGENHEIROS } & \multicolumn{2}{c|}{ MESTRES DE OBRAS } & \multicolumn{2}{c|}{ BENS MÓVEIS } & \multirow{2}{*}{ TOTAL } \\
\cline { 2 - 8 } & ESTADO & VAGAS & ESTADO & VAGAS & ESTADO & VAGAS & \\
\hline 1974 & SÃO PAULO & 09 & - & - & - & - & 09 \\
\hline 1975 & - & - & PERNAMBUCO & 50 & - & - & 50 \\
\hline 1976 & PERNAMBUCO & 30 & PERNAMBUCO & 30 & - & - & 30 \\
\hline 1977 & - & - & - & - & - & - & - \\
\hline 1978 & MINAS GERAIS & 22 & - & - & MINAS & 17 & 39 \\
\hline TOTAL & - & 52 & - & - & & 17 & 128 \\
\hline
\end{tabular}

Fonte: relatórios da Delegacia Regional Seplan/PR de 1976 e 1978. 
Ainda no âmbito da pós-graduação, ressalta-se a cooperação internacional efetivada pelo programa junto à Unesco, com vistas ao envio de profissionais do Iphan e das entidades estaduais para realizar cursos em instituições internacionais.

Henrique Oswaldo de Andrade esclarece que fez um acordo com o CNPq e a Capes para viabilizar a formação em cursos internacionais, especialmente com o lccrom, atentando-se às especificidades do patrimônio brasileiro:

(...) porque todo mundo ia para o curso de Roma, passava lá quatro anos no curso, toda manhã, aprendendo restauração de pedra e monumento romano, não é? Nessa linha. Obviamente você saía de lá com muito conhecimento, com técnicas muito sofisticadas e chegava aqui e não tinha aplicação nenhuma. (...) A ideia era o seguinte: a pessoa tinha que ter um curso no Brasil ou em qualquer outro lugar [no território] nacional, ter outra experiência de prática de obra e uma segunda etapa com um curso no exterior, que não era o último curso do Iccrom. No curso do lccrom, só chegava lá quem tinha passado por uma experiência, tinha passado por um curso em segundo lugar, ou Cuzco, para depois chegar lá. E montamos uma rede de mandar gente para fora. (...) Nós tínhamos o registro de todas as pessoas formadas na América Latina e todos os grandes técnicos que passaram por aqui. Então, a gente tinha um cadastro de pessoal nessa área que foi utilizado durante muito tempo ${ }^{73}$.

A intensa cooperação técnica internacional estabelecida com a Unesco também viabilizou a vinda ao Brasil de consultores especialistas em missões de curta duração (de um a três meses), para seminários organizados pelo programa, além do fornecimento de equipamentos e bibliografia específica. Desses encontros participavam ativamente os técnicos do lphan e das entidades estaduais.

Ressalte-se que não há notícia de que a especialidade conservação e restauração tivesse formação específica no Brasil antes dessas iniciativas. Assim, podemos afirmar que o programa, com um perfil extremamente executivo, teve grande importância para o amadurecimento conceitual e tecnológico da área no país. Segundo Froner,

A base de formação de especialistas gestada no Cecor (1980) e Cecre (1981) possibilitou a diversificação de linhas de pesquisas nos programas de pós-graduação strictu sensu das instituições de origem desses centros - como a área de concentração em "conservação e restauro" do Programa de Pós-Graduação em Arquitetura e Urbanismo da FAU-UFBA, com mestrado implantado em 1983 e doutorado em 2000; e a linha de pesquisa em "criação, crítica e preservação da imagem" do Programa de Pós-Graduação em Artes da EBAUFMG, com mestrado iniciado em 1998 e o doutorado em 2006 -, bem como a introdução de programas específicos, como o mestrado profissionalizante do Cecre (2009), dirigidos à construção de pesquisas acadêmico-científicas na área ${ }^{74}$.

Provavelmente, esse processo trouxe algumas tensões com relação ao Iphan: antes detentor, praticamente, exclusivo do saber relativo ao campo patrimonial, ao menos na execução das políticas públicas, seus técnicos tinham agora interlocutores com conhecimento especializado nas entidades estaduais. Além disso, ficavam mais claras as contradições existentes no próprio órgão, quebrando a mítica da existência de um pensamento único no lphan. Nesse sentido, Beatriz Kühl analisa o curso realizado em São Paulo:
73. Entrevista concedida pelo coordenador nacional do Programa de Cidades Históricas, Henrique Oswaldo de Andrade, a Lia Calabre e Lúcia Lippi em $07 / 04 / 2008$.

74. Cf. Yacyara Froner (2010, p. 51) 
76. Entrevista concedida pelo coordenador nacional do Programa de Cidades Históricas, de 1975 a 1985 , Henrique Oswaldo de Andrade, a Sandra Corrêa em 05/05/2011.
A Carta de Veneza fazia parte da bibliografia utilizada por Hugues de Varine-Bohan, que lecionou no curso. Nas aulas de Augusto da Silva Telles, a Carta foi extensa e fundamentadamente perscrutada, mas o arquiteto Fernando Machado Leal, que foi professor do curso e dizia seguir as recomendações das Cartas de Atenas e de Veneza, define restauração como "fazer voltar a edificação à sua feição primitiva", em flagrante contradição com as definições de ambas as cartas ${ }^{75}$.

Ademais, as discussões do campo do patrimônio cultural tinham nos cursos um ambiente especial: ao articular os profissionais das entidades executivas de políticas públicas (Iphan e órgãos estaduais) com o universo acadêmico e com os consultores da Unesco que também ministravam aulas nesses cursos, o programa fomentou uma circulação de ideias em escala considerável, se pensarmos no número de profissionais antes envolvidos na área de conservação e restauração.

A oportunidade viabilizada pelo $\mathrm{PCH}$ para qualificação dos profissionais das entidades executoras estaduais também toma importância quando analisada do ponto de vista da descentralização da política. Preocupação não exclusiva da área de patrimônio cultural, a falta de preparo dos funcionários de órgãos estaduais e municipais é muitas vezes apontada como empecilho para a execução de políticas federais em parcerias com essas esferas administrativas. A qualificação desejada geralmente envolve dois aspectos: formação profissional e envolvimento e entendimento das políticas a serem implementadas por parte da equipe. Os cursos financiados pelo PCH visavam, explicitamente, a criar recursos humanos adequados para a execução do programa. $\bigcirc$ envolvimento da equipe dava-se pela oportunização de desenvolvimento profissional aos técnicos estaduais, e seu entendimento acerca do programa por meio de seu modelo de gestão, como veremos à frente.

A institucionalização de órgãos estaduais para execução do programa é outro item importante a ser observado para avaliação do grau de descentralização da política. Segundo Henrique Oswaldo de Andrade, esse modelo visava a comprometer os estados com a política, mas encontrava algumas dificuldades quando da análise pelo grupo de trabalho em 1975:

Primeiro, falta de pessoal especializado. Segundo, a falta de entidade local que ficasse a cargo do Programa no Estado, porque o Município só entrou muito mais tarde. (...) você não tinha no Ceará, não tinha no Rio Grande do Norte. Então, iá havia uma recomendação de que cada Estado devia ter, pela Carta de Salvador (...). Então, uma das condições que a gente colocou que tivesse algum órgão que fosse um interlocutor principal e aquele que cuidaria lá. Por que? Porque a tendência de alguns ministérios era de que, cada vez que tinha um Programa desse, o ministério executava. Então, nossa proposta era ao contrário: como você compromete o Estado, o Estado assume, ele escolhe, em função até do uso que se vai dar, porque também a condição era essa, você tinha que ter uma restauração, mas você tinha que ter uma definição de uso pra ocupar. E a outra condição era de que você tivesse um compromisso de pelo menos, acho que dez anos, de manutenção. Sendo que muitas vezes nem precisava, porque se você punha alguma atividade permanente neste prédio, quem estava lá dentro tinha a obrigação de manutenção, você não precisava nem dar prazo ${ }^{76}$ 
Assim, temos duas questões: a existência de uma entidade executora, independente da sua especialização, e a institucionalização de órgãos específicos para preservação do patrimônio cultural nos estados. Nesse sentido, percebe-se que nas normas do programa não há exigência explícita para a constituição de órgãos específicos. Na Exposição de Motivos 076-B/73, a preferência para execução é bastante genérica:

Na tarefa de reconstituir as cidades e monumentos históricos do Nordeste, será dada prioridade, na execução, aos organismos locais tais como Fundações Especializadas, Empresas de Turismo e Bancos Estaduais de Desenvolvimento77.

Já a Portaria Interministerial 019/77, editada após a avaliação e revisão do programa, retira o foco das "empresas de turismo e bancos estaduais de desenvolvimento", mas também não especifica órgãos para a preservação do patrimônio cultural:

Art. $8^{\circ}$ - Terão preferência na execução dos trabalhos de restauração e preservação de bens móveis e imóveis, os órgãos e entidades estaduais e municipais especializados, da administração direta e indireta e as fundações supervisionadas ${ }^{78}$.

Apesar disso, a mesma portaria exigiu a apresentação de um "Programa Estadual de Restauração e Preservação para o período de 1977/79, indicando os monumentos a serem restaurados, o cronograma de execução, os roteiros turísticos recomendados e as fontes de recursos para fazer face à contrapartida exigida" e "comprovação do tombamento estadual do imóvel, concedendo-se aos estados que não tiverem legislação de tombamento prazo até junho de 1978 para cumprir esta condição". Tais exigências conformavam requisitos mínimos para a elaboração de uma política de preservação do patrimônio (edificado) estadual, que, dificilmente, poderiam ser elaborados e geridos com uma qualidade mínima que possibilitasse sua aprovação pela Comissão de Coordenação e Acompanhamento sem um quadro técnico especializado.

Analisando os dados consubstanciados no Quadro 9, feito com base em tabela apresentada no relatório de atividades da Delegacia Regional Seplan/ PR, em 1978, observamos que os estados de Sergipe, Alagoas e Ceará operaram por meio de entidades de desenvolvimento do turismo. Por outro lado, Bahia, Paraíba, Minas Gerais e Rio de Janeiro já possuíam órgãos específicos para a preservação do patrimônio cultural antes do programa.

Dessa forma, depreende-se que o PCH não teve papel tão preponderante na criação de órgãos estaduais específicos para a área de preservação quanto foram os Encontros de Governadores de 1970 e 1971. Contudo, observa-se que a criação desses órgãos naquele momento não foi acompanhada da provisão de estrutura administrativa, recursos consignados e legislação para proteção de patrimônio cultural. $\bigcirc$ Quadro 9 demonstra claramente tal situação: percebe-se que, de 1973 a 1977, os órgãos executores dos estados do Nordeste tiveram um acréscimo significativo no número de funcionários. Na Paraíba, a Fundação Cultural da Paraíba, criada em 1971, contava com orçamento de Cr\$50 mil, mas não
77. Cf. Ministério do Planejamento e Coordenação Geral (1973, p. 6).

78. Cf. Secretaria de Planejamento da Presidência da República $(1977 \mathrm{~b}, \mathrm{p}$. 4-5). 
tinha funcionários. Em 1977, com orçamento de Cr\$1,7 milhão, a equipe da fundação era formada por oito pessoas. Em Pernambuco, a Fundação do Patrimônio Histórico e Artístico passou de seis para 110 funcionários em quatro anos, e de um orçamento de $\operatorname{Cr} \$ 100$ mil para $\operatorname{Cr} \$ 7$ milhões.

Quadro 9: Evolução da estrutura das entidades estaduais

\begin{tabular}{|c|c|c|c|c|c|c|c|}
\hline \multirow{3}{*}{ ESTADO E ENTIDADE } & \multirow{3}{*}{$\begin{array}{c}\text { Data de } \\
\text { criação do } \\
\text { órgão }\end{array}$} & \multicolumn{3}{|c|}{1973} & \multicolumn{3}{|c|}{1977} \\
\hline & & \multirow{2}{*}{$\begin{array}{l}\text { Orçamento } \\
\text { para Patrimônio } \\
(\mathrm{Cr} \$ 1.000,00)\end{array}$} & \multicolumn{2}{|c|}{ Pessoal } & \multirow{2}{*}{$\begin{array}{c}\text { Orçamento } \\
\text { para Patrimônio } \\
(\mathrm{Cr} \$ 1.000,00)\end{array}$} & \multicolumn{2}{|c|}{ Pessoal } \\
\hline & & & Técnico & Auxiliar & & Técnico & Auxiliar \\
\hline $\begin{array}{c}\text { MARANHÃO } \\
\text { Fundação Cultural (1) }\end{array}$ & 1974 & 0 & 0 & 0 & 6.000 & 5 & 3 \\
\hline $\begin{array}{c}\text { PIAUÍ } \\
\text { Fundação Cultural }\end{array}$ & 1975 & 0 & 0 & 0 & 2.000 & 5 & 3 \\
\hline $\begin{array}{c}\text { PARAÍBA } \\
\text { Fundação Cultural }\end{array}$ & 1971 & 50 & 0 & 0 & 1.700 & 3 & 5 \\
\hline $\begin{array}{l}\text { RIO GRANDE DO NORTE } \\
\text { Fundação José Augusto }\end{array}$ & 1963 & 400 & 3 & 0 & 2.000 & 4 & 9 \\
\hline $\begin{array}{c}\text { PERNAMBUCO } \\
\text { Fundação do Patrimônio Histórico } \\
\text { e Artístico }\end{array}$ & 1973 & 100 & 3 & 3 & 7.000 & 20 & 90 \\
\hline $\begin{array}{c}\text { ALAGOAS } \\
\text { Empresa Alagoana de Turismo (2) }\end{array}$ & $\begin{array}{l}\text { Não se } \\
\text { aplica }\end{array}$ & 0 & 0 & 0 & 2.500 & 7 & 3 \\
\hline $\begin{array}{c}\text { SERGIPE } \\
\text { Empresa Sergipana de Turismo }\end{array}$ & $\begin{array}{l}\text { Não se } \\
\text { aplica }\end{array}$ & 2.500 & 0 & 0 & 7.000 & 8 & 3 \\
\hline $\begin{array}{c}\text { BAHIA } \\
\text { Fundação do Patrimônio Cultural }\end{array}$ & 1967 & 3.600 & 35 & 50 & 24.700 & 67 & 77 \\
\hline $\begin{array}{c}\text { CEARÁ } \\
\text { Empresa Cearense de Turismo }\end{array}$ & $\begin{array}{l}\text { Não se } \\
\text { aplica }\end{array}$ & $\mathrm{SI}$ & $\mathrm{SI}$ & SI & SI & $\mathrm{SI}$ & $\mathrm{SI}$ \\
\hline $\begin{array}{c}\text { MINAS GERAIS } \\
\text { Instituto Estadual do Patrimônio } \\
\text { Histórico e Artístico }\end{array}$ & 1971 & $\mathrm{SI}$ & $\mathrm{SI}$ & $\mathrm{SI}$ & $\mathrm{SI}$ & $\mathrm{SI}$ & $\mathrm{SI}$ \\
\hline $\begin{array}{c}\text { RIO DE JANEIRO Instituto Estadual } \\
\text { do Patrimônio Cultural }\end{array}$ & 1974 (3) & $\mathrm{SI}$ & $\mathrm{SI}$ & SI & $\mathrm{SI}$ & $\mathrm{SI}$ & $\mathrm{SI}$ \\
\hline $\begin{array}{l}\text { ESPÍRITO SANTO } \\
\text { Fundação Cultural }\end{array}$ & SI & $\mathrm{SI}$ & SI & SI & $\mathrm{SI}$ & $\mathrm{SI}$ & $\mathrm{SI}$ \\
\hline Total & & 6.650 & 41 & 53 & 52.900 & 119 & 192 \\
\hline
\end{tabular}

(1) Departamento de Patrimônio Histórico, Artístico e Paisagístico da Fundação Cultural.

(2) Substituída, para execução do programa em 1977, pelo Serviço de Engenharia do Estado de Alagoas.

(3) Substituindo o antigo Departamento de Patrimônio Histórico e Artístico, criado em 1964.

Fonte: Relatório Delegacia Regional Seplan/PR, 1978, complementada com dados constantes nos sítios eletrônicos das respectivas entidades ou correlatas. 
Provavelmente, as exigências técnicas do programa acabaram determinando a constituição de equipes para garantir sua execução. Com quadro de funcionários e orçamento crescentes, as entidades estaduais eram ainda estimuladas a qualificar as equipes por meio dos cursos promovidos pelo programa no Brasil e no exterior, além do contato estreito com o Iphan, como visto anteriormente. Outro fato interessante é que alguns dos órgãos criados inicialmente como secretarias ou departamentos foram transformados, para execução do programa, em fundações ou institutos, figura jurídica que na época possibilitava um funcionamento mais flexível e propício à execução mais eficiente de ações, amplamente incentivada pelo governo federal. A nosso ver, isso demonstra uma forte vinculação entre a estruturação dos órgãos e a implementação do PCH, como aponta Menezes ao analisar a criação da Fundarpe:

\begin{abstract}
A nova instituição se estruturou na figura jurídica de uma fundação criada pelo Banco do Estado de Pernambuco. Tal forma era a mais vantajosa para o Programa diante do interesse de se desejar um funcionamento com maior flexibilidade do que aquele em que as ações fossem de um órgão oficial, sujeito às normas burocráticas naturais de uma repartição pública. Por outro lado, uma fundação poderia legalmente receber doações. Os Estatutos daquela Fundação davam a ela foros de uma Secretaria de Cultura e com maior versatilidade. Era a independência da Cultura em sentido bem definido diante das ações voltadas à educação e que exigiam muita atenção do Estado de Pernambuco ${ }^{79}$.
\end{abstract}

A nova instituição se estruturou na figura jurídica de uma fundação criada pelo Banco do Estado de Pernambuco. Tal forma era a mais vantajosa para - Programa diante do interesse de se desejar um funcionamento com maior flexibilidade do que aquele em que as ações fossem de um órgão oficial, sujeito às normas burocráticas naturais de uma repartição pública. Por outro lado, uma fundação poderia legalmente receber doações. Os Estatutos daquela Fundação davam a ela foros de uma Secretaria de Cultura e com maior versatilidade. Era a independência da Cultura em sentido bem definido diante das ações voltadas à educação e que exigiam muita atenção do Estado de Pernambuco.

Essa indução se dava, exclusivamente, por questões operacionais, já que os recursos não poderiam ser utilizados para despesas correntes de administração do órgão estadual, nem os provenientes da contrapartida estadual. A Portaria $019 / 77$ ampliou as possibilidades da contrapartida a ser apresentada pelo estado, incluindo, com relação à EM 076-B/73, o aceite de despesas relativas a desapropriações, além da elaboração de projetos e planos já vigentes desde 1973. Dessa forma, a partir dos critérios e condições do programa, depreende-se que a estratégia era de que o PCH viabilizasse a execução de projetos e obras - que, sem dúvida, possibilitavam visibilidade política aos governos estaduais -, e, por outro lado, que os estados estruturassem uma política de preservação do patrimônio cultural que tivesse continuidade para além do programa dentro da máquina administrativa. Sant'Anna, ao analisar o esquema administrativo do $\mathrm{PCH}$, afirma que
79. Cf. José Luiz Mota Menezes (2008, p. 33). 
80. Cf. Marcia Sant'Anna (1995, p. 165).

81. Ver Marcia Sant'Anna (1995); Maria Cecília Londres Fonseca (2005); Vera Milet (1988).
Montou-se um sistema nacional de preservação, inédito na história do patrimônio do Brasil, no qual as instâncias financiadoras e normalizadoras ficavam localizadas no plano federal e as instâncias executoras executivas no estadual ${ }^{80}$.

Podemos concluir que o programa possibilitou a implementação da descentralização da política de preservação do patrimônio cultural - proposta, primeiramente, em nível geral pelo governo federal por meio da publicação do Decreto-Lei 200/67, e pelo MEC/Iphan aos governos estaduais, especificamente para a política de preservação nos Encontros de Governadores em 1970 e 1971. Assim, teríamos um caráter de continuidade da política na medida em que, a partir dos encontros, fomentou-se a criação dos órgãos e de legislação, e o programa viabilizou sua institucionalização com a oferta contínua e considerável de recursos e apoio técnico. Além disso, incentivou os estados que ainda não haviam criado entidades e legislações específicas a fazê-lo.

Por isso, concordamos com Sant'Anna quando afirma que o programa constituiu um sistema, estabelecendo a parceria e a articulação entre os dois entes federativos - União e estados - no período de 1973 a 1979. Pois, além de reconhecer como patrimônio cultural brasileiro os monumentos que representavam as identidades locais e ao viabilizar o financiamento de sua recuperação, considerava como atores fundamentais os técnicos que constituíam os quadros estaduais - incluindo-os nos programas de treinamento em pé de igualdade com os funcionários do Iphan - e, principalmente, utilizava as propostas estaduais para definição da política federal. Ou seja, os estados formulavam a política federal de preservação em conjunto com o Iphan e a Seplan, cumprindo um papel mais amplo do que simples executores. Entretanto, o programa não deu o importante passo da representação dos estados na Comissão de Coordenação e Acompanhamento, incluindo-os na sua estrutura decisória.

Por último, a forma de gestão do programa configura-se como sua característica mais marcante, ressaltada por outros autores que o analisaram, como Sant'Anna, Fonseca e Milet ${ }^{81}$. Imprimindo a marca do Ministério de Planejamento, o programa buscava planejamento, controle de execução e avaliação constantes. A estrutura central era bastante enxuta: segundo Henrique Oswaldo de Andrade, em Brasília havia cinco pessoas - em Recife, conforme verificado na documentação, provavelmente mais duas ou três pessoas dedicavamse ao $\mathrm{PCH}$. Assim, $\mathrm{Cr} \$ 735$ milhões e 172 projetos foram geridos, no âmbito central, durante sete anos por uma equipe que não chegava a dez pessoas. Um time reduzido como esse, por maior eficiência que possuísse, só poderia obter sucesso contando com as equipes das entidades estaduais e também com as do Iphan. Considerando que todos esses órgãos tinham carência de recursos, a cooperação entre Iphan, Seplan e estados uniu esforços com vistas a objetivos comuns e, portanto, potencializou suas ações.

Para articular esses vários agentes envolvidos, a coordenação tinha de ser bastante eficiente, evitando ruídos que pudessem prejudicar o andamento dos 
trabalhos. Com isso, percebe-se um controle, quando da fase Nordeste (19731976), pelo menos bimestral (com planilhas simples de acompanhamento de projetos) e semestral (relatórios completos). Anualmente, a Delegacia Regional da Seplan/PR também realizava relatórios de avaliação que consubstanciavam o histórico do ano, analisavam se os objetivos estavam sendo atingidos, apontavam dificuldades e soluções para superá-las.

Além dos relatórios, eram elaborados documentos de orientação às entidades estaduais, com modelos dos instrumentos a serem utilizados, com explicações sobre os conceitos e critérios para aprovação de projetos. Esses documentos passam a ser reunidos em manuais, a partir de 1977, contendo o passo a passo para a apresentação de projetos que pleiteavam recursos do programa.

Outra preocupação foi a construção de indicadores que demonstrassem o atingimento do objetivo de geração de renda pelo programa e ainda possibilitassem a comparação com outros programas do governo federal. Os indicadores escolhidos foram o número de empregos estáveis criados e os custos por metro quadrado de área agenciada e área restaurada, sendo considerados como "altamente positivo se comparado com os dados referentes aos projetos industriais e agropecuários aprovados pela Sudene no exercício de 1976"82. Essa análise indica que o custo do emprego gerado pelo $\mathrm{PCH}$ correspondia a 10\% do investido pela Sudene, demonstrado o potencial do patrimônio cultural para a geração de empregos nas cidades brasileiras.

Quadro 10: Indicadores do Programa de Cidades Históricas e Sudene - 1976 e 1977.

\begin{tabular}{|c|c|c|c|c|}
\hline & & Sudene - 1976 & PCH - 1976 & PCH - 1977 \\
\hline \multirow{3}{*}{ Restauração } & Investimento (Cr\$) & - & $35.405 .600,00$ & - \\
\hline & Área (m2) & - & $23.739,00$ & $40.000,00$ \\
\hline & Custo/m2 (Cr\$) & - & $1.491,45$ & $2.235,00$ \\
\hline \multirow{3}{*}{$\begin{array}{l}\text { Agenciamento } \\
\text { de espaços } \\
\text { públicos }\end{array}$} & Investimento $(\mathrm{Cr} \$)$ & - & $5.173 .090,00$ & - \\
\hline & Área $(\mathrm{m} 2)$ & - & $24.369,00$ & - \\
\hline & Custo/m2 (Cr\$) & - & 212,28 & $1.033,00$ \\
\hline \multirow{3}{*}{$\begin{array}{l}\text { Empregos } \\
\text { estáveis } \\
\text { diretos (un.) }\end{array}$} & Investimento (Cr\$) & - & $42.000 .000,00$ & $94.369 .882,00$ \\
\hline & $n^{\circ}$ empregos & - & 743,00 & $1.251,00$ \\
\hline & Custo/emp. (Cr\$) & - & $6.527,59$ & $5.435,56$ \\
\hline \multirow{3}{*}{$\begin{array}{l}\text { Projetos } \\
\text { industriais e } \\
\text { agropecuários }\end{array}$} & $\begin{array}{l}\text { Investimento total } \\
(\mathrm{Cr} \$)\end{array}$ & $18.783 .200 .000,00$ & - & - \\
\hline & $N^{\circ}$ empregos & $8.903,00$ & - & - \\
\hline & Custo/emp. (Cr\$) & $649.870,26$ & - & - \\
\hline
\end{tabular}

Fontes: Relatório de Atividades de 1977 do Programa de Reconstrução das Cidades Históricas do Nordeste, Delegacia Regional da Seplan/PR, 1978; Ofício de Renato Baumann das Neves a Henrique Oswaldo de Andrade, em 02 de março de 1977.
82. Cf. Renato Baumann das Neves (1977). 
83. Cf. Marcia Sant'Anna (1995, p. 183).

Em agosto de 1977, o programa viabilizou o treinamento das entidades estaduais e do Iphan, em colaboração com o Instituto de Programação e Orçamento (Inor), para utilização do Sistema Gerencial de Acompanhamento Físico e Financeiro (Sistema GRAFF). Segundo relatório de 1978, participaram do treinamento 28 técnicos dos estados do Maranhão, Piauí, Ceará, Rio Grande do Norte, Paraíba, Pernambuco, Alagoas, Sergipe, Bahia, Espírito Santo, Minas Gerais e Rio de Janeiro, além de representantes dos diversos distritos do Iphan.

Tal sistema era utilizado para acompanhar os programas de desenvolvimento coordenados pela Secretaria de Planejamento da Presidência da República visando ao controle da execução físico-financeira. De abril de 1978 em diante, todos os executores do programa (estados e Iphan) deveriam elaborar relatórios trimestrais com base no Sistema GRAFF para acompanhamento dos projetos, conforme o relatório da Seplan/PR de 1978.

Apesar de encontrarmos apenas um formulário preenchido de acordo com o sistema, correspondências trocadas entre Seplan/PR, Iphan e estados informam que o acompanhamento passou a ser realizado da forma pretendida. No entanto, como esses documentos não puderam ser analisados, não há como indicarmos a adesão dos órgãos e os dados apontados pelos gráficos resultantes de tal sistema.

\section{Conclusão}

Diferentemente do que se esperava, as experiências dos anos 70 não tornaram o Iphan superado. Ao contrário, serviram para consolidar mais ainda sua posição ${ }^{83}$.

No início desta pesquisa, revelamos o intuito de estudar o processo de formulação e implementação do Programa de Cidades Históricas. Para isso, o foco principal voltou-se às relações entre os principais agentes do programa durante sua construção e execução, a proposta e as ações para a construção de um Sistema Nacional de Preservação do Patrimônio Cultural, e se houve novas práticas institucionais no campo da preservação do patrimônio cultural no Brasil induzidas pelo programa.

Ao avaliar as relações de poder presentes durante a formulação e a implementação do Programa de Cidades Históricas, pudemos perceber que, embora haja vários atores envolvidos, a principal disputa deu-se entre Iphan e Ministério do Planejamento. Nesse sentido, coube outra pergunta: se o programa significou continuidade ou ruptura com relação à política que o Iphan vinha implementando para a preservação do patrimônio cultural.

Sobre isso, temos que o programa tinha como pressuposto, desde o início, a reestruturação do Iphan para receber o PCH posteriormente, o que demonstrava um reconhecimento daquela instituição como lócus para políticas de preservação. O movimento de reorganização do órgão, que se iniciou em 1975 
sob financiamento e articulação da coordenação do programa, instalada no Ministério do Planejamento, e realizada pela Secretaria de Modernização Administrativa, foi finalizado em 1979, quando o Iphan passou por uma reformulação que o colocou em outro patamar no governo federal.

Ademais, o modelo de gestão do Ministério do Planejamento, aplicado ao programa, permitiu que se fizessem comparações com outras políticas públicas federais, demonstrando, financeiramente, as vantagens do investimento em patrimônio cultural com relação, por exemplo, aos investimentos industriais da Sudene. Se por um lado o movimento políitico realizado inicialmente colocou o tema patrimônio na pauta da agenda do governo, o modelo de gestão manteve essa pauta junto ao Ministério do Planejamento. Portanto, o PCH, considerado um programa extremamente eficiente, obteve sucesso e legitimação no próprio ministério para manter o pleito junto ao Presidente da República. Acreditamos que essa foi a base para sua prorrogação até 1979, incluindo a solicitação de expansão aos estados do Rio de Janeiro, Minas Gerais e do Espírito Santo, e, posteriormente, a incorporação ao lphan.

É importante ainda observar que a implementação do programa, cerca de um ano após a realização do II Encontro de Governadores realizado pelo MEC/Iphan, significou a concretização do discurso do órgão do patrimônio junto aos estados brasileiros, ao direcionar investimentos significativos para serem executados pelos governos estaduais. Além disso, viabilizou apoio técnico para a formação de equipes qualificadas nos estados e induziu a estruturação de órgãos estaduais específicos voltados à cultura e à preservação do patrimônio cultural.

Assim, pode-se afirmar que, mesmo havendo certa disputa, a política de preservação do patrimônio cultural foi fortalecida com a implementação do PCH, especialmente no que se refere a sua visibilidade frente a outros agentes políticos e governamentais, bem como à sociedade brasileira. $O$ Iphan, como parceiro e depois coordenador do programa, fortaleceu-se da mesma forma. No entanto, quando afirmamos que a instituição se fortaleceu, não assumimos a parceria entre o Ministério do Planejamento e o Iphan como um processo pacífico e igual durante todo o período de formulação e implementação do PCH. Especialmente no início do programa, é possível perceber alguma tensão: se por um lado o Iphan participou de sua formulação, no início do PCH seu papel era meramente burocrático, estabelecendo-se duas políticas federais de preservação do patrimônio cultural paralelas, o que acreditamos ter gerado a insatisfação representada pela crítica de Augusto Silva Telles ainda em 1974.

Apesar disso, o Ministério do Planejamento demonstrava reconhecimento quanto à legitimidade do Iphan no campo do saber do patrimônio cultural, e parece não ter titubeado em inserir mudanças já em 1975 quando passou a exigir "planos de revitalização e valorização estaduais", como Silva Telles tinha proposto. Posteriormente, trouxe o Iphan ao centro da decisão, na fase que se iniciou em 1977, e, finalmente, cumpriv o objetivo de incorporar o programa ao instituto em 1979. Assim, se, na formulação, as duas instâncias estavam unidas e articuladas, 
nos primeiros momentos de implementação ocorreu um afastamento, estabelecendose, com os mesmos recursos, políticas paralelas. Após críticas e avaliações, iniciouse um processo de convergência em 1975, que se completaria com a alteração e a ampliação do programa em 1977.

Já no que se refere à construção de um sistema nacional pode-se dizer que obteve relativo sucesso na medida em que fomentou, mais do que a criação, a estruturação de órgãos de cultura e preservação do patrimônio cultural. Entretanto, no período estudado, o alcance se restringiu apenas à esfera estadual. Ao mesmo tempo, é preciso atentar para a necessidade de significativo empenho político e de condições (legais, humanas e financeiras) para a proposição e sustentação de órgãos governamentais. Dessa forma, talvez o período de sete anos seja curto para estabelecer, de fato, um sistema envolvendo as três esferas administrativas do Estado brasileiro. Considerando as experiências realizadas no período imediatamente posterior ao estudado, essa análise poderá ser enriquecida com a investigação sobre as ações do Iphan na década de 1980. Contudo, tal constatação não retira a importância do processo ocorrido durante toda a década de 1970, em que o Conselho Federal de Cultura, o MEC e o Iphan iniciaram uma aproximação efetiva com os estados, e o Programa de Cidades Históricas possibilitou a concretização dessa articulação.

A indução de novas práticas no lphan e instituições estaduais nos parece o principal legado do programa, especialmente nos aspectos conceituais e de gestão. $\bigcirc$ PCH permitiu o exercício conceitual da intervenção em áreas urbanas. Assim, mesmo que no período estudado se vislumbre uma atuação ainda focada nos monumentos, consideramos que as práticas implantadas pelo $\mathrm{PCH}$, na busca gradual pelos conceitos trabalhados já ao fim da década de 1960 pelo Iphan e Unesco, possibilitaram um campo fértil para o debate sobre o tema na década de 1970. Esses debates foram se qualificando ao longo do processo, juntamente com a entrada de novos atores - as equipes estaduais e outros órgãos federais, dos quais se destaca a CNPU -, e a melhor qualificação do próprio Iphan, já que a circulação de ideias proporcionada pelos cursos, palestras, contatos com consultores externos e apoios técnicos, ocorreu nos âmbitos interno e externo às instituições.

I phan foi induzido a uma prática de compartilhamento e parceria com outros órgãos de governo e com universidades. Como vimos na pesquisa, apesar de a articulação com instituições de ensino e com outras esferas de governo estar presente nos discursos do Iphan bem antes da criação do programa, é com ele que a instituição obterá os meios e, ainda, será induzida a efetivar tal pactuação. Assim, de órgão executor da política, o lphan também passa a exercer o papel de coordenador.

Merece destaque ainda a forma de gestão implementada pelo Ministério do Planejamento, com acompanhamento rigoroso e avaliações periódicas. Certamente, o modelo utilizado foi fundamental para a estruturação de uma proposta de descentralização da política. A coordenação do programa emitia, constantemente, documentação explicitando conceitos, critérios, modelos a serem 
utilizados, indicadores etc., apresentando aos parceiros, de forma clara, como o $\mathrm{PCH}$ deveria ser executado.

Acreditamos que esse modelo de gestão, subsidiado em diversos manuais e outros materiais de orientação, e de periódico retorno aos parceiros dos resultados e avaliação, permitiu que uma equipe central enxuta coordenasse um programa complexo, com muitos recursos e junto a agentes tão diversos e distantes espacialmente. Esses fatos estabeleceram uma articulação eficiente e garantiram a execução do programa.

Finalmente, concluímos que o Programa de Cidades Históricas foi idealizado de maneira alinhada às políticas então em pleno debate e implementação nos governos Médici e Geisel, especialmente as coordenadas pelo Ministério do Planejamento, relacionadas à descentralização das políticas federais, ao desenvolvimento regional e ao planejamento/investimento integrados. $\bigcirc \mathrm{PCH}$ investiu um montante de recursos nunca antes viabilizado para o setor, e colocou o tema na agenda dos governos federal e estaduais, certamente configurando uma das principais políticas já implementadas para a preservação do patrimônio cultural.

É inegável a lógica econômica matriz do Programa de Cidades Históricas. Ressalte-se que o que parecia, por um lado, um caminho arriscado para essa área, na verdade possibilitou um alinhamento com as políticas internacionais de preservação que ocorriam na época (mesmo que depois tenham sido criticadas e revistas).

$\bigcirc$ fato de o Programa de Cidades Históricas ser considerando por alguns autores como uma política limitada conceitualmente, provavelmente desconsidera o contexto em que foi implementada e a complexidade presente na formulação e na implementação de uma política nacional articulada entre diversos agentes, em que o pensamento hegemônico é impossível e o tempo de amadurecimento é maior.

A amplitude de atuação do programa e a grande quantidade e qualidade de documentação disponível sobre essa política sugerem linhas de pesquisa das mais diversas. Nesse sentido, a dissertação que originou este artigo pretendeu ser apenas uma das muitas abordagens possíveis sobre essa importante política de preservação do patrimônio cultural brasileiro realizada na década de 1970. Assim, buscamos contribuir, para além de descrever a trajetória do Programa de Cidades Históricas, para uma reflexão sobre a necessidade de conhecer e avaliar as políticas públicas de preservação do patrimônio cultural. Tal conhecimento poderá subsidiar decisões coerentes com relação à sua contínua construção e reconstrução, o que é fundamental para proposições que exigem forte comprometimento político e institucional, em longo prazo, como a construção de um sistema nacional, que permanece como um objetivo na pauta política do lphan até os dias atuais. 


\section{REFERÊNCIAS}

\section{FONTES PRIMÁRIAS}

Arquivo Central do Iphan, Brasília

Série Programa de Cidades Históricas

COUTO, Élcio Costa [Ofício 1135/78] 16 out.1978, Rio de Janeiro [Brasil] [para] Norman Jones, Washington [Estados Unidos].

GRUPO DE TRABALHO INTERMINISTERIAL. Relatório. Proposta preliminar para o "Programa Integrado de Reconstrução das Cidades Barrocas do Nordeste, com fins turísticos". Coordenador: Fernando Quintela. Brasília, 1973.

GRUPO DE TRABALHO INTERMINISTERIAL. Relatório de atividades. Proposta para o "Programa Integrado de Reconstrução das Cidades Históricas do Espírito Santo, de Minas Gerais e do Rio de Janeiro". Coordenador: Henrique Oswaldo de Andrade. Brasília, 1975.

MINISTÉRIO DA EDUCAÇÃO E CULTURA. Departamento de Assuntos Culturais. Anais do II Encontro de Governadores. Rio de Janeiro, 1973.

MINISTÉRIO DA EDUCAÇÃO E CULTURA. Exposição de Motivos $n^{\circ} 320$ de 8 de novembro de 1979. Eduardo Portella e Antônio Delfim Netto. Brasília, 1979.

MINISTÉRIO DO PLANEJAMENTO E COORDENAÇÃO GERAL. Exposição de Motivos $n^{\circ}$ 0301$B$, de 22 de dezembro de 1972. João Paulo dos Reis Velloso e Jarbas Passarinho. Brasília, 1972 .

MINISTÉRIO DO PLANEJAMENTO E COORDENAÇÃO GERAL. Exposição de Motivos $n^{\circ}$ 076$B$, de 31 de maio de 1973. João Paulo dos Reis Velloso e Jarbas Passarinho. Brasília, 1973.

MINISTÉRIO DO PLANEJAMENTO E COORDENAÇÃO GERAL. Delegacia Regional do Recife. Relatório do "Programa Integrado de Reconstrução das Cidades Históricas do Nordeste com sua utilização para fins turísticos”. Recife, 1974.

MINISTÉRIO DO PLANEJAMENTO E COORDENAÇÃO GERAL. Programa de Cidades Históricas: Relatório - 75. Brasília, 1975.

NEVES, Renato Baumann das. [Ofício] 02.mar.1977, Brasília (Brasil][para] Henrique Oswaldo de Andrade, Brasília.

SECRETARIA DE PLANEJAMENTO DA PRESIDÊNCIA DA REPÚBLICA. Delegacia Regional do Recife. Relatório de avaliação do "Programa Integrado de Reconstrução das Cidades Históricas do Nordeste com sua utilização para fins turísticos”. Recife, 1976.

SECRETARIA DE PLANEJAMENTO DA PRESIDÊNCIA DA REPÚBLICA. Exposição de Motivos $n^{\circ}$ 024, de 02 de fevereiro de 1977a. João Paulo dos Reis Velloso e Ney Aminthas de Barros Braga. Diário Oficial [da República Federativa do Brasil], Brasília, 11 fev.1977. Sec. 1, parte I. 
SECRETARIA DE PLANEJAMENTO DA PRESIDÊNCIA DA REPÚBliCA. Portaria Interministerial Seplan/MEC/MIC $n^{\circ} 019$ de 4 de março de 1977b. João Paulo dos Reis Velloso, Ney Aminthas de Barros Braga e Ângelo Calmon de Sá. Diário Oficial [da República Federativa do Brasil], Brasília, 8 mar.1977. Sec. 1, parte I, p. 2615-2617.

SECRETARIA DE PLANEJAMENTO DA PRESIDÊNCIA DA REPÚBLICA. Manual de Instruções: Programa de Cidades Históricas. Brasília, 1977c.

SECRETARIA DE PLANEJAMENTO DA PRESIDÊNCIA DA REPÚBLICA. Programa de Cidades Históricas: 1978. Brasília, 1978.

SECRETARIA DE PLANEJAMENTO DA PRESIDÊNCIA DA REPÚBLICA. Exposição de Motivos $n^{\circ}$ 065, de 12 de março de 1979. João Paulo dos Reis Velloso. Brasília, 1979.

VELLOSO, João Paulo Reis. [Carta] 8 mar. 1979 Brasília[Brasil] [para] António Ortiz Mena Washington [Estados Unidos].

Arquivo Central do Iphan, Rio de Janeiro

Série Assuntos Internacionais

ANDRADE, Rodrigo M. F. de. [Carta]. 20 out. 1966, Rio de Janeiro [Brasil] [para] Raymundo Augusto de Castro Moniz de Aragão, Rio de Janeiro.

SOEIRO, Renato. [Ofício] 17 abr. 1967 Rio de Janeiro [Brasil] [para] Raymundo Augusto de Castro Moniz de Aragão, Rio de Janeiro.

SOEIRO, Renato. [Carta] 12 nov. 1968 Rio de Janeiro [Brasil] [para] Carlos Chagas Filho, Rio de Janeiro.

Decretos

BRASIL. Decreto-Lei $n^{\circ} 200$, de 25 de fevereiro de 1967. Dispõe sobre a organização da Administração Federal, estabelece diretrizes para a Reforma Administrativa e dá outras providências.

\section{LIVROS, ARTIGOS E TESES}

CALABRE, Lia. Politicas e conselhos de cultura no Brasil: 1967-1970. Fundação Casa de Ruy Barbosa, sem data. Disponível em <http://www.casaruibarbosa.gov.br/dados/DOC/artigos/ aj/ FCRB_LiaCalabre_Politicas_e_Conselhos_de_Cultura_no_Brasil.pdf>, acesso em 04 mai. 2012.

CENTRO DE ESTUDOS AVANÇADOS DE CONSERVAÇÃO INTEGRADA. Apresentação do Curso de Qualificação de Mestres de Obras em Conservação e Restauro. Disponível em http:// www.ceci-org.br. Acesso em 01 jul.2012. 
CORRÊA, Sandra Rafaela Magalhães. O Programa de Cidades Históricas (PCH): Por uma política integrada de preservação do patrimônio cultural - 1973/1979. 2012. Dissertação (Mestrado em Arquitetura e Urbanismo) - Programa de Pós-Graduação em Arquitetura e Urbanismo, Universidade de Brasília, Brasília, 2012.

FONSECA, Maria Cecília Londres. O patrimônio em processo: trajetória da política federal de preservação no brasil. 2.ed. rev. ampl. Rio de Janeiro: Editora UFRJ; MinC - Iphan, 2005.

FRANCISCONI, Jorge Guilherme; SOUZA, Maria Adélia. Política Nacional de Desenvolvimento Urbano: estudos e proposições alternativas. Brasília: Ipea/Iplan, 1976 (Série Estudos para o Planejamento 15).

FRONER, Yacyara. Conservação e restauração: a legitimação da ciência. Acervo, Rio de Janeiro, v. 23, $\mathrm{n}^{\circ} 2$, p. 47-56, jul.-dez. 2010.

GONÇALVES, José Reginaldo Santos. A retórica da perda: os discursos do patrimônio cultural no Brasil. Rio de Janeiro: Editora UFRJ; Iphan, 1996.

GUSMÃO, Fernanda Maria Buarque de. Empoderamento e preservação do patrimônio cultural: o caso do Programa de Recuperação e Revitalização de Núcleos Históricos, Projeto Piloto Olinda/PE, 1981-1989.2011. Dissertação (Mestrado Profissional em Gestão Pública para o desenvolvimento do Nordeste) - Centro de Ciências Aplicadas, Universidade Federal de Pernambuco, Recife, 2011.

INSTITUTO DO PATRIMÔNIO HISTÓRICO E ARTÍSTICO NACIONAL - IPHAN. Compromisso de Brasília. Disponível em: <http://portal.iphan.gov.br>, acesso em 05 mai. 2012.

KÜHL, Beatriz Mugayar. Notas sobre a Carta de Veneza. Anais do Museu Paulista - História e Cultura Material, São Paulo, v.18, n.2, p. 287-320, jul.-dez. 2010.

LEAL, Claudia Feierabend Baeta (org.). As missões da Unesco no Brasil: Michel Parent. Tradução Rejane Maria Lobo Vieira. Rio de Janeiro: Iphan, Copedoc, 2008.

LOWANDE, Walter Francisco Figueiredo. Os sentidos da preservação: história da arquitetura e práticas preservacionistas em São Paulo (1937-1986). 2010. Dissertação (Mestrado em Ciências Humanas e Sociais) - Instituto de Ciências Humanas e Sociais, Universidade Federal de Ouro Preto, Mariana, 2010.

MAIA, Tatyana de Amaral. O patrimônio cultural brasileiro em debate: a ação do Conselho Federal de Cultura (1967-1975). Revista CPC, São Paulo, n.11, p. 60-86, nov. 2010/abr. 2011. Disponível em: <http://www.usp.br/cpc/v1/imagem/conteudo_revista_arti_arquivo_pdf/ 03_11r09.pdf>, acesso em 04 mai. 2012.

Por um Sistema Cultural Integrado: a Ação do Conselho Federal de Cultura (1967-1975). Apresentado no VI ENECULT, Salvador, 2010. Disponível em <http://www.cult. ufba.br/wordpress/24481.pdf>. Acesso em 04 mai. 2012.

MENEZES, José Luiz Mota. Ainda chegaremos lá: história da Fundarpe. Recife: Fundarpe, 2008.

MILET, Vera. A teimosia das pedras: um estudo sobre a preservação do patrimônio ambiental no Brasil. Olinda: Prefeitura de Olinda, 1988. 
OLIVEIRA, Francisco de. O Estado e o Urbano no Brasil. Revista Espaço e Debates, São Paulo, vol. 6, p. 36-54, 1982.

PARENT, Michel. Un Vasto Programa de Turismo Cultural en el Brasil. El Correo, Unesco, Paris, Año XXI, p. 12-15, 1968).. Disponível em: <http://www.unesco.org/new/en/>, acesso em 25 abr. 2012.

PESSOA, Álvaro. Nota explicativa. In: PESSOA, Álvaro (org.). Direito do urbanismo: uma visão sócio-jurídica. Rio de Janeiro: IBAM, 1981, p. XV-XVIII.

RUA, Maria das Graças. Análise de políticas públicas: conceitos básicos. Florianópolis: Departamento de Ciências da Administração-UFSC; Brasília: CAPES;UAB, 2009. Disponível em: <http://vsites.unb.br/ceam/webceam/nucleos/omni/observa/downloads/ pol_publicas. pdf>, acesso em 26 jun. 2012.

SANT'ANNA, Marcia. Da cidade-monumento à cidade-documento: A trajetória da norma de preservação de áreas urbanas no Brasil (1937-1990). 1995. Dissertação (Mestrado em Arquitetura e Urbanismo) - Universidade Federal da Bahia, Salvador, 1995.

SANTOS FILHO, José Camilo dos. O recente processo de descentralização e democratização e da gestão democrática do brasil. Revista Brasileira de Estudos Pedagógicos. Brasília, v. 73, n. 174, p. 219-241, mai/ago, 1992. Disponível em <http://www.rbep.inep.gov.br>. Acesso em 20 mai.2011.

SCHMIDT, Benicio Viero. O Estado e a política urbana no Brasil. Porto Alegre: Editora da UFRGS, 1983.

SOUZA, Celina. Políticas Públicas: uma revisão da literatura. Sociologias, Porto Alegre, ano 8, no 16, p. 20-45, jul/dez 2006. Disponível em: <http://www.scielo.br/pdf/soc/ n16/a03n16. pdf>, acesso em 26 jun. 2012.

UNESCO. 1967, Año del Turismo Internacional. El Correo, Paris, Ano XIX, p. 05-09, dez. 1966 a. Disponível em: <http://www.unesco.org/new/en/>, acesso em 25 abr. 2012.

VILLAÇA, Flávio. Uma contribuição para a história do planejamento urbano. In: DEÁK, Csaba; SCHIFFER, Sueli Ramos (org.). O processo de urbanização no Brasil. São Paulo: Edusp; Fupam, 1999, p. 171-242.

\section{ENTREVISTAS}

ANDRADE, Henrique Oswaldo de. Entrevista concedida pelo coordenador nacional do Programa de Cidades Históricas a Lia Calabre e Lúcia Lippi em 07/04/2008. Projeto Política cultural e cidadania, Fundação Getúlio Vargas. Não publicado.

ANDRADE, Henrique Oswaldo de. Entrevista concedida pelo coordenador nacional do Programa de Cidades Históricas, de 1975 a 1985, a Sandra Corrêa em 05/05/2011.

ANDRADE, Henrique Oswaldo de. Entrevista concedida pelo coordenador nacional do Programa de Cidades Históricas de 1975 a 1985 a Sandra Corrêa em 06/07/2012.

Artigo apresentado em 20/01/2016. Aprovado em 08/06/2016. 
